\title{
Provisioning strategies of Antarctic fur seals and chinstrap penguins produce different responses to distribution of common prey and habitat
}

\author{
Taro Ichiii ${ }^{1, *}$, John L. Bengtson ${ }^{2}$, Peter L. Boveng ${ }^{2}$, Yoshimi Takao ${ }^{3}$, John K. Jansen ${ }^{2}$, \\ Lisa M. Hiruki-Raring ${ }^{2}$, Michael F. Cameron ${ }^{2}$, Hiroshi Okamura ${ }^{1}$, \\ Tomonari Hayashi ${ }^{1}$, Mikio Naganobu ${ }^{1}$
}

\author{
${ }^{1}$ National Research Institute of Far Seas Fisheries, 2-12-4 Fukuura, Kanazawa, Yokohama 236-8648, Japan \\ ${ }^{2}$ National Marine Mammal Laboratory, Alaska Fisheries Science Center/NOAA, 7600 Sand Point Way NE, Bldg. 4, \\ Seattle, Washington 98115, USA \\ ${ }^{3}$ National Research Institute of Fisheries Engineering, 7620-7, Hasaki, Kamisu, Ibaraki 314-0408, Japan
}

\begin{abstract}
Central-place foragers that must return to a breeding site to deliver food to offspring are faced with trade-offs between prey patch quality and distance from the colony. Among colonial animals, pinnipeds and seabirds may have different provisioning strategies, due to differences in their ability to travel and store energy. We compared the foraging areas of lactating Antarctic fur seals and chinstrap penguins breeding at Seal Island, Antarctica, to investigate whether they responded differently to the distribution of their prey (Antarctic krill and myctophid fish) and spatial heterogeneity in their habitat. Dense krill concentrations occurred in the shelf region near the colony. However, only brooding penguins, which are expected to be time-minimizers because they must return frequently with whole food for their chicks, foraged mainly in this proximal shelf region. Lactating fur seals and incubating penguins, which can make longer trips to increase energy gain per trip, and so are expected to be energy-maximizers, foraged in the more distant (>20 km from the island) slope and oceanic regions. The shelf region was characterized by more abundant, but lower-energy-content immature krill, whereas the slope and oceanic regions had less abundant but higher-energy-content gravid krill, as well as high-energy-content myctophids. Furthermore, krill in the shelf region undertook diurnal vertical migration, whereas those in the slope and oceanic regions stayed near the surface throughout the day, which may enhance the capture rate for visual predators. Therefore, we suggest that the energy-maximizers foraged in distant, but potentially more profitable feeding regions, while the time-minimizers foraged in closer, but potentially less profitable regions. Thus, time and energy constraints derived from different provisioning strategies may result in sympatric colonial predator species using different foraging areas, and as a result, some central-place foragers use suboptimal foraging habitats, in terms of the quality or quantity of available prey.
\end{abstract}

KEY WORDS: Habitat selection · Antarctic fur seals · Chinstrap penguins · Antarctic krill $\cdot$ Myctophid fishes $\cdot$ Provisioning offspring $\cdot$ Energy-maximizer $\cdot$ Time-minimizer

\section{INTRODUCTION}

Foraging is clearly related to an animal's fitness so that animals are likely to be under natural selection to be efficient foragers. Optimal foraging theory assumes that animals feed in a way that maximizes their net rate of energy intake (energy/time, Pyke et al. 1977). There are 2 simple strategies to accomplish this. The energymaximizer tries to maximize the energy intake, while the time-minimizer tries to minimize the time spent foraging to meet nutritional requirements (Stephens \& Krebs 1986). These 2 approaches represent the end- 
points of a continuum of foraging behaviors which are constrained by environmental and life history factors (for example, patchiness of food availability or time of year in the life history cycle).

During the breeding season, most animals face the problem of obtaining food for themselves and for their offspring. Colonial animals face the additional constraint of having to return from feeding areas to a breeding site to deliver food to offspring. These animals, which are called central-place foragers since they carry food back to a central place, have restricted foraging ranges (in comparison to non-breeding individuals) to avoid offspring starvation. Central-place foragers are predicted to choose the closest suitable foraging area to the colony (Orians \& Pearson 1979).

Among central-place foragers, breeding penguins and lactating fur seals have different constraints on provisioning offspring (Costa 1991). During the incubation period penguins need energy primarily to restore their body reserves lost during fasting. Because incubation shifts can span several days, penguins have a relatively long time to do this, and hence they have the potential to make long trips at sea. Thus, they can be expected to use strategies that maximize the energy acquired in a foraging trip. In contrast, during the chick-brooding period, they must replenish their reserves and provide food to their chicks. They store prey in the stomach and later feed the chicks by regurgitation. They cannot increase the food delivery to offspring beyond the stomach capacity, and so they must increase the rate of energy delivery to chicks by minimizing their time at sea. Thus, chick-brooding penguins can be expected to use strategies that minimize the time required to return sufficient resources to their offspring. Fur seals use lactation as a method to concentrate and deliver energy to their offspring. They store energy as fat when at sea and convert this to milk for delivery to the pups. Thus, fur seals, as compared with chick-brooding penguins, can be expected to use energy maximizing strategies, such as concentrating energy content delivered to the young by increasing trip duration (e.g. Costa 1991). Therefore, a comparison of foraging areas of female fur seals and penguins breeding sympatrically provides an opportunity to study whether the energy-maximizer and time-minimizer respond differently to the distribution of their common prey and habitat.

Antarctic fur seals Arctocephalus gazella and chinstrap penguins Pygoscelis antarctica occur sympatrically during the breeding season in the waters north of the South Shetland Islands near the Antarctic Peninsula, and are, respectively, the main mammal and bird consumers of Antarctic krill Euphausia superba. Female fur seals give birth to their single pups from mid-November to late December. Only female seals provision their offspring. Normal foraging trip duration is about 4 to $5 \mathrm{~d}$, alternating with shore-based pupsuckling bouts of 1 to $2 \mathrm{~d}$ (Walker and Boveng 1995). Pups depart rookeries when they are weaned in late March and April. Chinstraps establish nests and typically lay a 2-egg clutch in early November (Jansen 1996). Both parents undertake long incubation shifts (5 to $10 \mathrm{~d}$ ) followed by foraging trips of similar duration (Williams 1995). Upon hatching 1 or 2 chicks in late December, parents begin making daily foraging trips while alternating brooding duties with their mates. During late January chicks are left unattended (crèche phase), and adults continue daily feedings until chicks fledge in mid-February (Jansen et al. 2002). Thus, the breeding seasons of these 2 species are highly synchronous.

The purpose of this study was to determine whether provisioning constraints of Antarctic fur seals and chinstrap penguins produce different responses to shifts in the distribution of their common prey and the spatial heterogeneity of the marine habitat. We identified and described the ecological characteristics of the foraging areas of lactating Antarctic fur seals and chinstrap penguins breeding at Seal Island, South Shetland Islands (Fig. 1a). Since these predators feed not only on krill, but also on myctophids (Jansen et al. 1998, Casaux et al. 1998, Osman et al. 2004), both prey species were studied. We analyzed the diets and foraging area (habitat) selection of fur seals and penguins during mid-breeding season to compare their responses.

\section{MATERIALS AND METHODS}

The specific procedures of this study were (1) following the predators during their feeding trips to sea in order to locate important foraging areas using shipboard/satellite tracking; (2) using hydroacoustic and net sampling during shipboard tracking to evaluate the distribution and abundance of prey species in relation to oceanographic features; (3) investigating the diet of the predators; (4) contrasting the foraging strategies of these predators early and mid-way through the reproductive season.

During 1994/95 (the Antarctic summer reproductive season of December 1994 to February 1995), oceanographic conditions, prey distribution and predator foraging ranges in the waters north of Elephant Island were studied in 2 phases to elucidate temporal changes. The first phase of the shipboard study took place early in the predators' breeding season (16 to 26 December), and the second phase took place near the middle of the breeding season (19 to 29 January) (Fig. 1b). Just prior to each phase, we investigated 
oceanographic conditions and prey distribution along the $55^{\circ} \mathrm{W}$ line of longitude (Fig. 1b), as part of a multinational collaborative study (Kim et al. 1998). Data obtained from that investigation were also used here. During 1990/91, we conducted a preliminary tracking study of foraging predators from January 1 to 8 , and results are included here. Diet samples of predators were collected between the 1987/88 and 1994/95 seasons.

Oceanographic observation. Throughout the shipboard study, surface temperature, salinity, and chlorophyll a ( $\mathrm{chl} a$ ) were recorded continuously by the EPCS (Electronic Plankton Counting and Sizing System, Honchigo). For each parameter, values averaged over

\section{(a)}

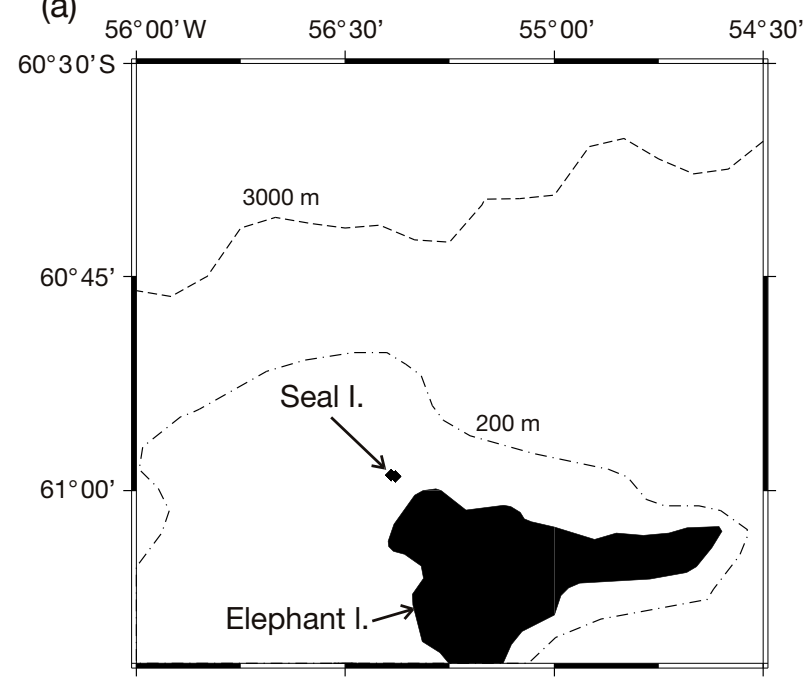

$60 \mathrm{~s}$ (80 to $200 \mathrm{~m}$ in distance at cruising speed) were stored. Surface chl a was monitored with a Turner Designs fluorometer calibrated using spectrophotometrically determined chl a concentrations from 6 to 7 discrete samples, each drawn from the surface at the beginning and end of each survey phase (26 samples in total). Temperature profiles of the water column in the foraging areas were obtained using expendable bathythermographs (XBTs). Contour lines representing the temperature profiles were computed using a contour plot subroutine of GMT, the Generic Mapping Tools software package (http://gmt.soest. hawaii.edu).

Prey study. Acoustic survey: Acoustic data were collected throughout the shipboard study (except when towing nets) with an echo sounder (Furuno Electric FQ-72) utilizing 2 frequencies simultaneously, viz. $50 \mathrm{kHz}$ and $120 \mathrm{kHz}$. Acoustic volume backscattering data were integrated vertically over $10 \mathrm{~m}$ depth intervals for depth ranges of 10 to $150 \mathrm{~m}$, and over $50 \mathrm{~m}$ depth intervals for depth ranges of 150 to $400 \mathrm{~m}$. The shallowest depth was sometimes changed to $20 \mathrm{~m}$ in order to exclude surface aeration noise caused by rough seas. Data were continuously integrated horizontally at intervals of 100 pings, equivalent to $150 \mathrm{~s}$ ( 200 to $500 \mathrm{~m}$ in distance at cruising speed) in the case of the 10 to $400 \mathrm{~m}$ depth range. System calibrations were conducted with a $38.1 \mathrm{~mm}$ tungsten carbide standard sphere for each survey phase, while the ship was at anchor in Admiralty Bay, King George Island, South Shetland Islands.

During the acoustic survey, 2 types of echoes were identified based on visual comparison of scattering lay-

(b)

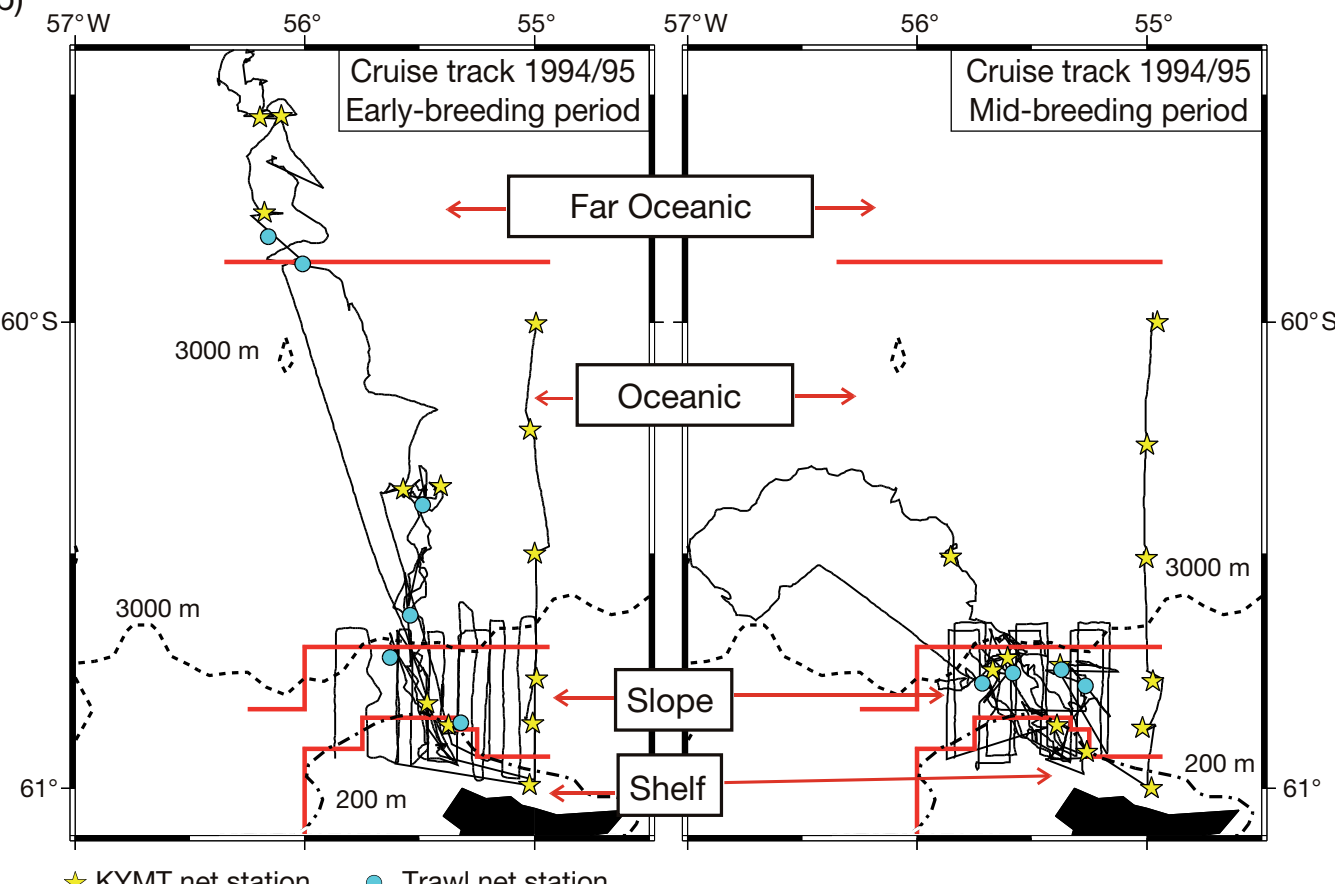

Fig. 1 (a) Location of Seal Island in the Southern Ocean. (b) Cruise tracks and net sampling stations during the early and mid-breeding periods of 1994/95, with 200 and $3000 \mathrm{~m}$ depth contours. Thick red lines divide ocean regions. KYMT indicates Kaiyo Maru Midwater Trawl for zooplankton sampling 
ers at the 2 different frequencies. Those echoes were classified as 'krill' type or 'myctophid' type, based on net samples. 'Krill' type echos, which were of similar intensities at both 50 and $120 \mathrm{kHz}$, occurred in the upper $150 \mathrm{~m}$ depth range throughout the day in the shelf, slope and oceanic regions. In contrast, the 'myctophid' type echo, which was more intense at $50 \mathrm{kHz}$ than at $120 \mathrm{kHz}$ (dB difference $\geq 4.0 \mathrm{~dB}$ ), occurred between 150 and $400 \mathrm{~m}$ depth during daytime and between the near surface and $300 \mathrm{~m}$ depth at night. 'Myctophid' type echos were not recorded in the shelf region. This occurrence pattern corresponded to the characteristic myctophid distribution, which is closely associated with the Antarctic Deep Water off the shelf region (Sabourenkov 1990). Therefore, volume back scattering values at $120 \mathrm{kHz}$ in the depth range of 10 to $150 \mathrm{~m}$ were considered to come from krill, and those at $50 \mathrm{kHz}$ in the depth range of 150 to $400 \mathrm{~m}$ were considered indicative of myctophids. This classification method underestimated myctophid density at night when some of the fish migrated into the upper $150 \mathrm{~m}$ and swam closer to the surface (Kozlov et al. 1990, Sabourenkov 1990).

For the purpose of estimating krill density, krill target strength (TS in $\mathrm{dB}$ ) at $120 \mathrm{kHz}$ was defined as a function of body length ( $L$ in $\mathrm{mm}$ ) as proposed by SC-CAMLR (1991):

$$
\text { TS }=34.85(\log L)-127.45
$$

The relationship of krill wet weight in mg (W) as a function of standard length (L) was taken from Siegel (1986):

$$
W=0.00115 L^{3.457}
$$

Since the TS of myctophids was unknown, the mean backscattering area per square nautical mile $\left(\mathrm{S}_{\mathrm{A}}\right.$, in units of $\mathrm{m}^{2} \mathrm{n} \mathrm{mile} \mathrm{e}^{-2}$, equivalent to $0.29 \mathrm{~m}^{2} \mathrm{~km}^{-2}$ ) at $50 \mathrm{kHz}$ in the depth range of 150 to $400 \mathrm{~m}$ was used as an abundance index (Hewitt \& Demer 1993, Demer \& Hewitt 1995).

To generate prey distribution maps, acoustic measurements were undertaken continuously during predator tracking. Additional acoustic surveys were made at the beginning and end of each phase for the shipboard study by covering areas of approximately $20 \times$ 20 nautical miles $(37 \times 37 \mathrm{~km})$ north of Seal Island (Fig. 1b). Each survey comprised 6 to 10 north-south transect lines. Contour lines representing prey densities were generated using GMT.

Net sampling: Krill samples were collected in foraging areas and along the $55^{\circ} \mathrm{W}$ line of longitude using a KYMT net (Kaiyo Maru Midwater Trawl: mouth area $9 \mathrm{~m}^{2}$, mesh size $3.4 \mathrm{~mm}$ ), towed at a speed of 2 to 3 knots (3.7 to $5.5 \mathrm{~km} \mathrm{~h}^{-1}$ ) (Fig. 1b). The KYMT was towed at swarm depth when large swarms were detected acoustically in the foraging areas, and obliquely from $200 \mathrm{~m}$ to the surface at net stations along the $55^{\circ} \mathrm{W}$ line of longitude. From each haul, 150 krill were haphazardly selected for body length measurements and determination of maturity stages; from catches smaller than 150, all individuals were analyzed. Body length was measured to the nearest $\mathrm{mm}$ from the anterior tip of the rostrum to the posterior end of the telson. Maturity stages were identified according to the classification of Makarov \& Denys (1981).

Fish samples were collected in foraging areas of predators using a large trawl (effective mouth diameter ca. $30 \mathrm{~m}$, inner mesh size $13 \mathrm{~mm}$ at the cod end) (Fig. 1b). Trawling speed was 3 to 4 knots (5.5 to $7.3 \mathrm{~km}$ $\mathrm{h}^{-1}$ ), with trawling depth restricted to within the predators' diving depth ranges, i.e. shallow $(0$ to $50 \mathrm{~m})$ or middle $(50$ to $100 \mathrm{~m}$ ) depth ranges. Trawls at greater (200 to $250 \mathrm{~m}$ ) depths were conducted to identify prey species observed on the acoustic records. Trawls were principally conducted at night in areas where tracked predators dived intensively. The total weight of each net sample was measured. Sub-samples were sorted into species for large catches, while entire samples were sorted for small catches. Species abundance was expressed in wet weight of the catch $(\mathrm{kg})$ per hour of trawling.

Predator study. Deployment of instruments on predators: During the early breeding period (late November and early December) of 1994/95, 12 female fur seals were each equipped with a VHF radio transmitter (Advanced Telemetry System [ATS], $45 \mathrm{~mm}$ wide $\times 25 \mathrm{~mm}$ high $\times 40 \mathrm{~mm}$ long, weight $60 \mathrm{~g}$ ) and a TDR (Time depth recorder, Wildlife Computers, $27 \mathrm{~mm}$ in diameter $\times 150 \mathrm{~mm}$ long, weight $170 \mathrm{~g}$ ) (Table 1). Another 9 female fur seals were fitted with satellitelinked transmitters (PTTS; Toyocom, $35 \mathrm{~mm}$ diameter $\times$ $190 \mathrm{~mm}$ long, weight $265 \mathrm{~g}$ ) in this period (mid-December). Eleven and 10 chinstrap penguins were each equipped with a VHF transmitter (ATS, $14 \mathrm{~mm}$ diameter $\times 68 \mathrm{~mm}$ long, weight $20 \mathrm{~g})$ and a TDR $(36 \mathrm{~mm}$ wide $\times 22 \mathrm{~mm}$ high $\times 110 \mathrm{~mm}$ long, weight $107 \mathrm{~g}$, or $64 \mathrm{~mm}$ long $\times 38 \mathrm{~mm}$ wide $\times 13 \mathrm{~mm}$ high, weight $50 \mathrm{~g}$ ) during the early (incubation period, mid-December) and mid-breeding (chick-brooding period, midJanuary) seasons, respectively.

During 1990/91, 16 female fur seals and 11 chinstrap penguins were fitted with VHF transmitters and TDRs in the early breeding period (mid-December) and midbreeding period (chick-brooding period, late December), respectively (Table 1).

Shipboard tracking: Four yagi directional antennae were mounted near the top of the mast of the RV 'Kaiyo Maru' to assist in locating fur seals and penguins at sea. These antennae were connected to an automatic direction finding system (ATS) that guided the ship 
Table 1. Numbers of VHF transmitters, time-depth recorders (TDR), and satellite location transmitters (PTTs) deployed by species, year, and stage of the breeding season

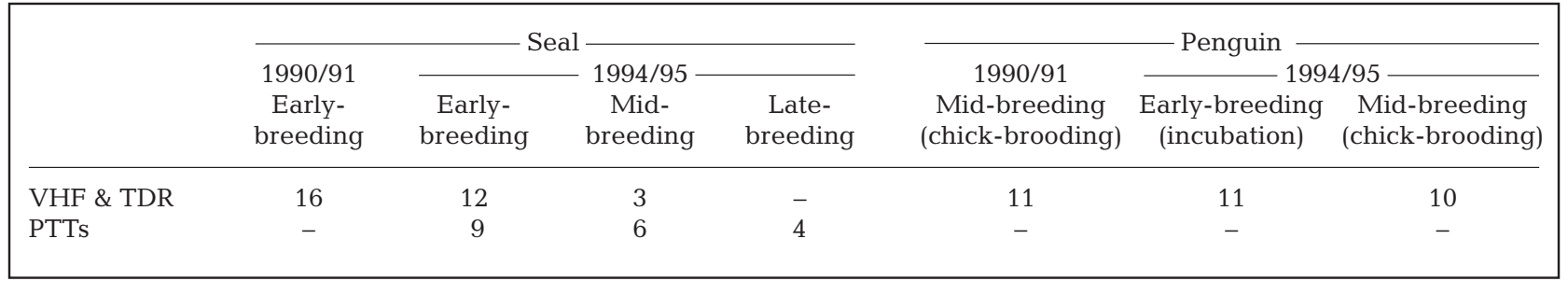

while it followed the target individuals. The automatic direction finding system was operated around the clock as follows. The ship waited off Seal Island (approximately $3.6 \mathrm{~km}$ from shore) until the penguin or fur seal departed to the open sea on a feeding trip. Penguins were tracked until they returned to Seal Island or until they appeared to be starting their return leg. Locations of penguins were obtained approximately every 30 to $60 \mathrm{~min}$ (ca. 2 to $4 \mathrm{~km}$ ). Fur seals on multi-day trips were usually followed until they appeared to be starting their return to the island. Locations of seals were obtained approximately every 1 to $2 \mathrm{~h}$ (ca. 2 to $6 \mathrm{~km}$ ).

Satellite tracking of fur seals: The locations of PTTs were collected through the ARGOS system (CLS/Service ARGOS Processing Center, Toulouse, France), which provided a Location Quality (LQ) code for each location fix. These were 3, 2, 1, 0, A and B in order of decreasing location quality. We estimated the accuracy (average deviation in $\mathrm{km}$ ) of these codes as $0.16 \pm 0.01$ $($ mean $\pm \mathrm{SE}, \mathrm{n}=61), 0.28 \pm 0.02(\mathrm{n}=78), 0.75 \pm 0.09(\mathrm{n}=$ $79), 2.35 \pm 0.64(\mathrm{n}=16), 0.70 \pm 0.09(\mathrm{n}=90)$ and $6.93 \pm$ 1.41 ( $\mathrm{n}=88)$, respectively, by placing the PTTs at the US field camp $\left(60^{\circ} 59.5^{\prime} \mathrm{S}, 55^{\circ} 34.5^{\circ} \mathrm{W}\right)$ at Seal Island prior to the tracking study. All LQ code locations were used to determine foraging ranges, after eliminating improbable locations that required a fur seal to exceed the typical maximum swim speed $\left(7 \mathrm{~km} \mathrm{~h}^{-1}\right)$ reported in Boyd (1996).

Fur seal diet: Information on Antarctic fur seal diet was determined from 78 scats collected around breeding sites from the early (December) to late (March) breeding period in 1990/91 and 5 scats from the early (December) to mid-breeding (February) period in 1994/95. Krill and myctophid occurrences were based upon the presence of krill chitin and myctophid otoliths in the scats. Remnants of squid were observed only rarely (density in scat $<1 \%$ of myctophid density), and hence were excluded from the analysis. One regurgitated sample, composed exclusively of semi-digested krill, was collected in the mid-breeding period (February) of 1994/95. Two hundred krill individuals haphazardly collected from that sample were used to determine body length and sex composition using the method of Hill (1990).

Penguin diet: Penguin diet samples were collected using a stomach flushing method (Wilson 1984) from $1987 / 88$ to $1989 / 90$ and $1992 / 93$ to $1994 / 95$. Each year, 30 to 50 diet samples were collected during the midbreeding period (chick-brooding period, January and February) from 1987/88 to $1989 / 90$ and $1992 / 93$ to 1993/94. Five diet samples each were collected during the early (incubation period, December) and midbreeding (chick-brooding period, January) periods in 1994/95. Samples were drained and sorted into primary prey categories (i.e. krill, fish) to evaluate the quantitative contribution of each prey species to the diet by estimating the original mass from partially digested and intact stomach contents. Remnants of other prey species, such as squid and amphipods, were observed only rarely $(<1 \%$ by weight), and hence excluded from the analysis.

Estimation of the original mass of krill in the diet was based on the number of krill individuals, their body length class composition and body weight for each length class. The number of krill in the diet was determined by halving the number of krill eyes. Between 150 and 400 krill individuals were haphazardly subsampled from each diet sample for determination of body length and sex composition, applying the method used for fur seal diet analysis. The body weight of krill was estimated from the weight-length relationship (Siegel 1986).

Estimation of the original mass of fish in the diet was based on the number of fish individuals, their body lengths and weights. Otoliths were used for species identification (Hecht 1987, Williams \& McEldowney 1990); the number of each fish species in the diet was determined by halving the number of otoliths. The original fish mass was estimated from fish body lengths, in turn estimated from otolith lengths using regression equations derived from Williams \& McEldowney (1990) and Hecht (1987).

Caloric value of prey. To obtain caloric values of krill (according to maturity stage) and fish, their biochemical compositions (water, carbohydrate, protein, lipid, 
etc.) were analyzed in the Japan Food Research Laboratories. Krill and fish samples were obtained by the KYMT plankton net and mid-water trawl net, respectively, during 1994/95. The caloric value of each prey item was calculated on the basis of: carbohydrate $=$ $17.4 \mathrm{~kJ} \mathrm{~g}^{-1}$, protein $=23.7 \mathrm{~kJ} \mathrm{~g}^{-1}$, lipid $=39.6 \mathrm{~kJ} \mathrm{~g}^{-1}$, dietary fiber $=8.4 \mathrm{~kJ} \mathrm{~g}^{-1}$ and ash + water $=0 \mathrm{~kJ} \mathrm{~g}^{-1}$. In determining the energy density of krill, the energy bound in the chitin was not included, since seals and penguins cannot digest chitin.

Statistical analysis. Foraging area (habitat) selection by seals and penguins was statistically analyzed based on duration of stay (hours) in each habitat, measured by the shipboard tracking. Since fur seals and some penguins were tracked only on their outbound trips until they appeared to be starting their return, we used the outbound trip of all individuals tracked. The 2 species differed in foraging trip duration; seals took trips of much longer duration than penguins. Hence, to compare habitat preferences of the 2 species, we used indices standardized by outbound trip time.

Many statistical methods are available to analyze resource or habitat selection data (Manly et al. 2002). However, classical models that can deal with continuous variables such as time have some problems, especially when the data contain many zeros. For example, compositional analysis (Aebischer et al. 1993), which is an application of multivariate analysis of variance to analyze resource selection data, has an inflated Type I error rate in simulation studies on data with frequent zeros (Dasgupta \& Alldredge 2002, Bingham \& Brennan 2004). We propose a simple method for analyzing habitat selection by multiple species based on continuous variables.

Suppose the habitat selection data are structured as in Table 2. The hypothesis for investigation proposes that different species selected different habitats. When there is repetition within an individual, the same individual possibly has a pattern of (i.e. correlation in) habitat selection. We used a strategy that treats the repeated measures as a random effect (Pawitan 2001).

Table 2. Structure of the habitat selection data for species (predator type) $i(i=1,2,3)$. The value in each cell is the duration of the stay spent by each animal (unit: hour)

\begin{tabular}{|lcccc|}
\hline Species $i$ & Observation & Habitat 1 & $\ldots$ & Habitat $j$ \\
\hline \multirow{4}{*}{ Individual 1} & 1 & $t_{i 111}$ & $\ldots$ & $t_{i j 11}$ \\
& $\vdots$ & $\vdots$ & $\ddots$ & $\vdots$ \\
$\vdots$ & $m_{i 1}$ & $t_{i 11 m_{i 1}}$ & & $t_{i j 1 m_{i 1}}$ \\
& $\vdots$ & $\vdots$ & $\vdots$ & $\vdots$ \\
Individual $n_{i}$ & $\vdots$ & $t_{i 1 n_{i} 1}$ & $\ldots$ & $t_{i j n_{1} 1}$ \\
& $m_{i n_{i}}$ & $\vdots$ & $\ddots$ & $\vdots$ \\
& & $t_{i 1 n_{i} m_{i n_{i}}}$ & $\ldots$ & $t_{i j n_{i} m_{i n_{i}}}$ \\
\hline
\end{tabular}

The duration of the lth stay $\left(t_{i j k l}\right)$ in habitat $j$ by individual $k$ of species $i$ takes the form

$$
t_{i j k l}=\alpha_{i}+\alpha_{i}\left(\beta_{i j}+b_{i j k}\right)+\varepsilon_{i j k l}
$$

where $i=1, \ldots, I, j=1, \ldots, J, k=1, \ldots, n_{i r} l=1, \ldots, m_{i k t}$ $b_{i j k} \approx N\left(0, \sigma_{b}^{2}\right)$ (random effects) and $\varepsilon_{i j k l} \approx N\left(0, \sigma_{i}^{2}\right) . \beta_{i j}$ and $b_{i j k}$ in the regression parameters have the constraint $\sum_{j=1}^{J} \beta_{i j}=\sum_{j=1}^{J} b_{i j k}=0$ so that $\alpha_{i}$ is the mean duration of the stay in a habitat per individual of species $i$. Using $\alpha_{i} \beta_{i j}$ as regression coefficients, we can extract information on habitat selection taking the difference in the duration of stay among species into account. The expected ratio of the stay in habitat $j$ by species $i$ is $1+\beta_{i j}$. We call the standardized $W_{i j}=\left(1+\beta_{i j}\right) / J$, the habitat selection index (HSI), where:

$$
\sum_{j} w_{i j}=\sum_{j} \frac{\left(1+\beta_{i j}\right)}{J}=\frac{1}{J} \sum_{j}\left(1+\beta_{i j}\right)=1
$$

The variable that we deal with is the staying time, which is defined only for positive values. This is inconsistent with the assumption of a normal distribution. However, the quantity of interest is the ratio of the 'average' staying time in a specific habitat by each species, which, under the central limit theorem is normally distributed, even if the observed data are not normally distributed (Pawitan 2001). We diagnosed the appropriateness of the model by using the residual

$$
\hat{D}_{i j k}=\sqrt{m_{i k}}\left(\frac{1}{m_{i k}} \sum_{l=1}^{m_{i k}} t_{i j k l}-\hat{\alpha}_{i}-\hat{\alpha}_{i} \hat{\beta}_{i j}\right) / \hat{\sigma}_{i}
$$

which should be asymptotically distributed as $\mathrm{N}(0,1)$ when the model is correct.

All the parameters were estimated by maximizing the likelihood (Pawitan 2001) as shown in Appendix 1. We used a model selection approach based on AIC (Akaike Information Criterion; Akaike 1973, Johnson \& Omland 2004) to investigate whether the HSI varied among species. Because chinstrap penguins at this colony employ 2 distinct foraging strategies (Jansen et al. 1998), we separated this species into daytime and overnight foragers to allow testing for differences between these strategies, as well as between the species; hereafter we refer to fur seals, daytime foraging penguins, and overnight foraging penguins as different predator types. Because the ratio of the total sample size $(n)$ to the number of parameters $(K)$ was small (say $n K<40$ ) in our study, we used AICc (small sample unbiased $\mathrm{AICc}$ ),

$$
\mathrm{AICc}=\mathrm{AIC}+2 K(K+1) /(n-K-1)
$$

according to the recommendation by Burnham \& Anderson (1998). 
Table 3. Parameter $\left(\beta_{i j}\right)$ for habitat selection index of each predator (i) for each habitat $j . \mathrm{M}_{0}$ : no difference in habitat selection among predator types, i.e. $\beta_{i j}=\mathrm{c}_{j}($ all $i, j)$. $\mathrm{M}_{\mathrm{I}}$ : predator type 1 and 2 had the same selection, but predator type 3 was different, i.e. $\beta_{i j}=c_{j}(i=1,2$, all $j), \beta_{3 j}$ freely estimated. $M_{F}$ : all 3 predator types had different selections (full model). AICc: small sample unbiased Akaike Information Criterion

\begin{tabular}{|lccc|}
\hline AICc model & Seal & $\begin{array}{c}\text { Overnight foraging } \\
\text { penguins } \\
(i=2)\end{array}$ & $\begin{array}{c}\text { Daytime foraging } \\
\text { penguins } \\
(i=3)\end{array}$ \\
\hline $\mathrm{M}_{0}$ & $\mathrm{C}_{j}$ & $\mathrm{C}_{j}$ & $\mathrm{C}_{j}$ \\
$\mathrm{M}_{\mathrm{I}}$ & $\mathrm{C}_{j}$ & $\mathrm{C}_{j}$ & Free \\
$\mathrm{M}_{\mathrm{II}}$ & $\mathrm{C}_{j}$ & Free & $\mathrm{C}_{j}$ \\
$\mathrm{M}_{\mathrm{III}}$ & Free & $\mathrm{C}_{j}$ & $\mathrm{C}_{j}$ \\
$\mathrm{M}_{\mathrm{F}}$ & Free & Free & Free \\
\hline
\end{tabular}

AICc values of the following 5 models were compared (Table 3):

$\mathrm{M}_{0}$ : no difference in habitat selection among predator types, i.e. $\beta_{i j}=c_{j}($ all $i, j)$.

$\mathrm{M}_{\mathrm{I}}$ : Fur seals (predator type 1) and overnight foraging penguins (predator type 2) had the same selection, but daytime foraging penguins (predator type 3 ) were different, i.e. $\beta_{i j}=c_{j}(i=1,2$, all $j), \beta_{3 j}$ freely estimated.

$\mathrm{M}_{\mathrm{II}}$ : Fur seals and daytime foraging penguins had the same selection, but overnight foraging penguins were different, i.e. $\beta_{i j}=C_{j}(i=1,3$, all $j), \beta_{2 j}$ freely estimated.

$\mathrm{M}_{\text {III }}$ : Overnight and daytime foraging penguins had the same selection, but fur seals were different, i.e. $\beta_{i j}=C_{j}(i=2,3$, all $j), \beta_{1 j}$ freely estimated.

$\mathrm{M}_{\mathrm{F}}$ : All 3 predator types selected different habitats (full model).

If $\mathrm{AICc}$ of the full model, in which habitat selection indices of each species are estimated freely, was smaller than any other model, we could plausibly support the hypothesis that different predator types differ in their habitat selection.

Asymptotic standard errors of habitat selection indices obtained from the best model based on AICC were calculated from the Fisher information matrix (Pawitan, 2001) as shown in Appendix 2. The statistical language $\mathrm{R}$ ( $\mathrm{R}$ Development Core Team 2005) was used for these analyses of foraging habitat selection.

\section{RESULTS}

\section{Oceanographic environments}

Oceanographic observations during seal tracking in 1994/95 indicated a distinct salinity front (33.8 to $34.2 \mathrm{psu}$ ) along the slope (200 to $3000 \mathrm{~m})$ north of
Elephant Island (Fig. 2a). Another front was observed further north, at about $59^{\circ} 45^{\prime} \mathrm{S}$, with downwelling features (Fig. 2a). These fronts are termed the 'slope' and 'oceanic' fronts, respectively, hereafter. We divided the study area into 4 regions (Fig. $1 \mathrm{~b})$ : shelf $(\leq 200 \mathrm{~m})$, slope (200 to $3000 \mathrm{~m})$, oceanic ( $\geq 3000 \mathrm{~m}$, south of $\left.59^{\circ} 52^{\prime} \mathrm{S}\right)$, and far oceanic $\left(\geq 3000 \mathrm{~m}\right.$, north of $\left.59^{\circ} 52^{\prime} \mathrm{S}\right)$, which included the oceanic front.

Surface chl a concentrations tended to be high $\left(\geq 1.5 \mathrm{mg} \mathrm{m}^{-3}\right)$ on the shelf and along the slope and oceanic fronts during the early breeding period (Fig. 2a). In the oceanic region, they tended to be low $\left(\leq 0.5 \mathrm{mg} \mathrm{m}^{-3}\right)$, but higher values $\left(\geq 1.5 \mathrm{mg} \mathrm{m}^{-3}\right)$ were observed locally, such as adjacent to the slope region, and near an iceberg $\left(60^{\circ} 22^{\prime} \mathrm{S}, 55^{\circ} 30^{\prime} \mathrm{W}\right)$, where a tracked penguin stayed for more than $2 \mathrm{~d}$ (iceberg $\mathrm{B}$ in Fig. 2b). During the mid-breeding period surface chl a concentrations were relatively high $\left(\geq 1.25 \mathrm{mg} \mathrm{m}^{-3}\right)$ in the slope front and shelf (Fig. 2c) areas. In the oceanic region, on the other hand, they were low $\left(\leq 0.5 \mathrm{mg} \mathrm{m}^{-3}\right)$, especially north of $60^{\circ} 25^{\prime} \mathrm{S}$.

\section{Krill distribution}

During seal and penguin early breeding periods in 1994/95, krill were distributed widely as far as $180 \mathrm{~km}$ offshore from Seal Island (Fig. 3a). Mean biomasses $\left(\mathrm{g} \mathrm{m}^{-2}\right)$ were $63.0,34.0,18.4$ and 16.4 for the shelf, slope, oceanic and far oceanic regions, respectively. These are all relatively high values. During the midbreeding period, on the other hand, krill distribution contracted to within $65 \mathrm{~km}$ from Seal Island. Mean biomasses $\left(\mathrm{g} \mathrm{m}^{-2}\right)$ were $75.7,22.8$ and 8.8 for the shelf, front and oceanic regions, respectively. Hence, the oceanic regions were poor in krill standing stock later in the breeding period.

According to the acoustic data collected during the early breeding period of 1994/95 (Fig. 1b), krill showed little diurnal vertical migration, remaining in the upper $60 \mathrm{~m}$ throughout the day in the shelf region, and in the upper $40 \mathrm{~m}$ in the slope, oceanic, and far oceanic regions (Fig. 4). During the mid-breeding period, on the other hand, krill undertook diurnal vertical migration on the shelf, occupying a deeper range (40 to $140 \mathrm{~m}$ deep) in the daytime and a shallower range ( 0 to $80 \mathrm{~m}$ ) at night. In the slope and oceanic regions, krill showed little diurnal vertical migration, staying in the upper layer (ca. $40 \mathrm{~m}$ ) throughout the day. Krill in the offshore region tended to aggregate near the strong thermocline (ca. $30 \mathrm{~m}$ depth) between the warm surface water and cold 'Winter Water' during both the early and mid-breeding periods.

Size class compositions of krill differed between the shelf and the oceanic regions during both periods 

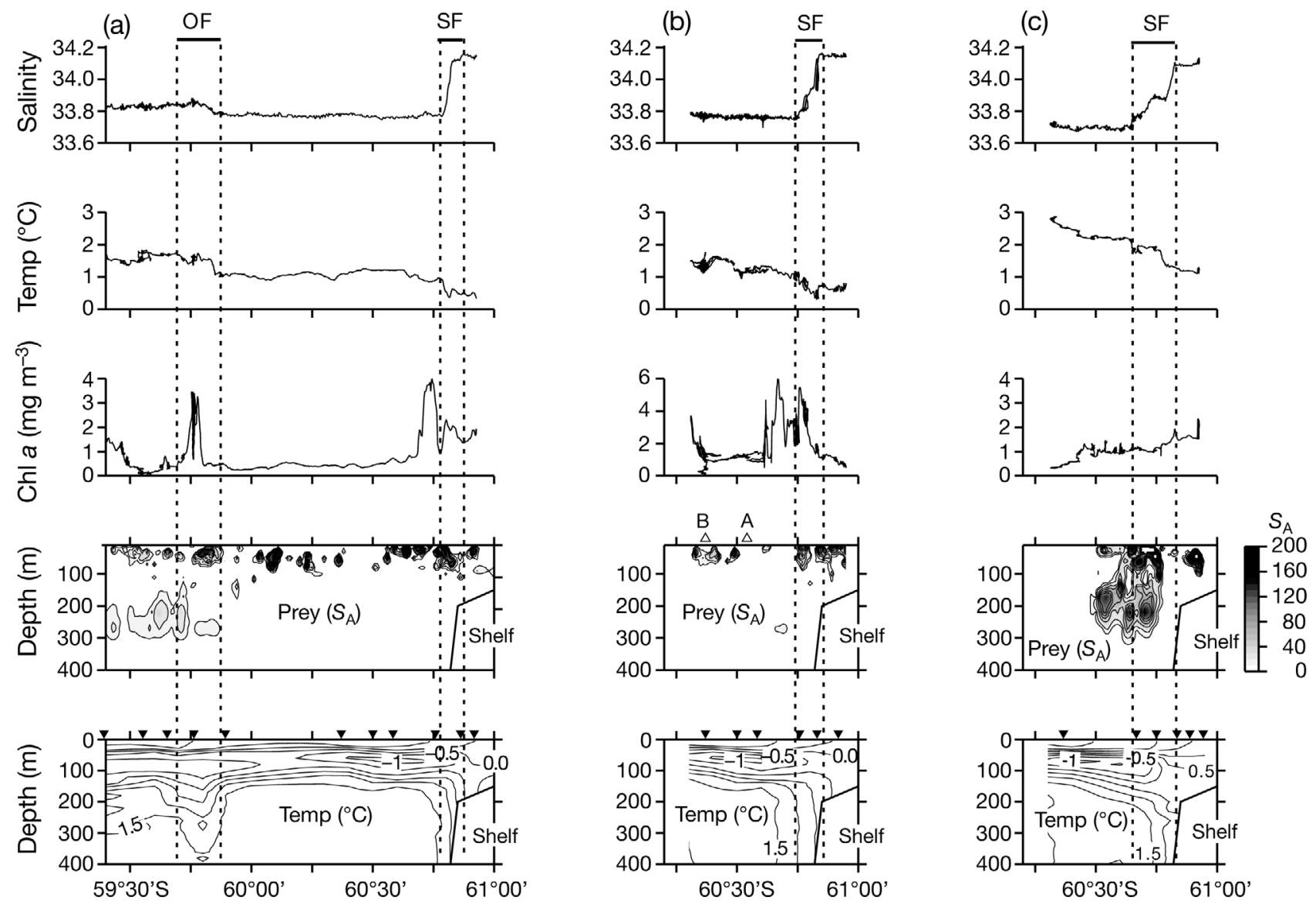

Fig. 2. Surface water salinity, temperature, chl $a$, vertical distributions of prey (krill and myctophids) and temperature isotherms during tracking of (a) a fur seal during the early breeding period (18 to 21 December), (b) a chinstrap penguin during the early breeding period (incubation period, 23 to 25 December), and (c) a fur seal during the mid-breeding period ( 26 to 27 January) in 1994/95. Prey density shown in $S_{\mathrm{A}}\left(\mathrm{m}^{2} \mathrm{n} \mathrm{mile}^{-2}\right)$ at $50 \mathrm{kHz}$ by $10 \mathrm{~m}$ depth intervals. SF: slope front. OF: oceanic front. $\mathbf{\nabla}$ : expendable bathythermograph (temperature) XBT station locations. $\Delta$ : locations of icebergs on which the tracked penguin stayed for $5 \mathrm{~h}(\mathrm{~A})$ and $54 \mathrm{~h}(\mathrm{~B})$ during its foraging trip in (b)

(Fig. 5). Mid- and small-sized krill (35 to $46 \mathrm{~mm}$ in modal length) were dominant on the shelf, compared with large-sized krill (ca. $50 \mathrm{~mm}$ in modal length) including gravid females in the oceanic and far oceanic regions. In the slope region, krill were mid-sized in the early breeding period, being replaced by large individuals in the mid-breeding period, reflecting a contraction of krill distribution toward the island. The modal length of krill was smaller in the shelf region than in the combined slope, oceanic, and far oceanic region during the early $(\mathrm{p}=0.03)$ and mid-breedings $(\mathrm{p}=$ 0.009) periods (Mann-Whitney $U$-test).

\section{Myctophid distribution}

During the predator early breeding period of 1994/95, myctophids occurred at relatively high densities (ca. $200 \mathrm{~m}^{2} \mathrm{n}$ mile $^{-2}$ ) in the vicinity and to the north of the oceanic front (Fig. 3b). Downwelling features of the Southern Antarctic Circumpolar Current Front (Brandon et al. 2004) corresponded to the southern edge of myctophid concentrations (Fig. 2a). South of the front, the densities were too low for detection by the echo sounder, except along the westward track of the $3000 \mathrm{~m}$ depth contour, where a low but detectable density (ca. $100 \mathrm{~m}^{2} \mathrm{n}$ mile ${ }^{-2}$ ) occurred (Fig. 3b). A similar result was obtained by night-time trawling, with a large catch per unit of trawling time (CPUE; $185 \mathrm{~kg} \mathrm{~h}^{-1}$ on average) in the vicinity of the oceanic front, but only a small CPUE to the south $\left(19 \mathrm{~kg} \mathrm{~h}^{-1}\right.$ on average in the slope front region) (Fig. 3c). Mean densities $\left(\mathrm{m}^{2}\right.$ $\mathrm{n}$ mile $^{-2}$ ) were $6.6,28.3,35.3$ and 77.2 for the shelf, slope, oceanic and far oceanic regions, respectively.

During the mid-breeding period, a high density area $\left(600 \mathrm{~m}^{2} \mathrm{n}\right.$ mile $\left.{ }^{-2}\right)$ of myctophids occurred in the vicinity of the slope front (Fig. 3b). Upwelling features of the Southern Boundary of the Antarctic Circumpolar Cur- 
(a)

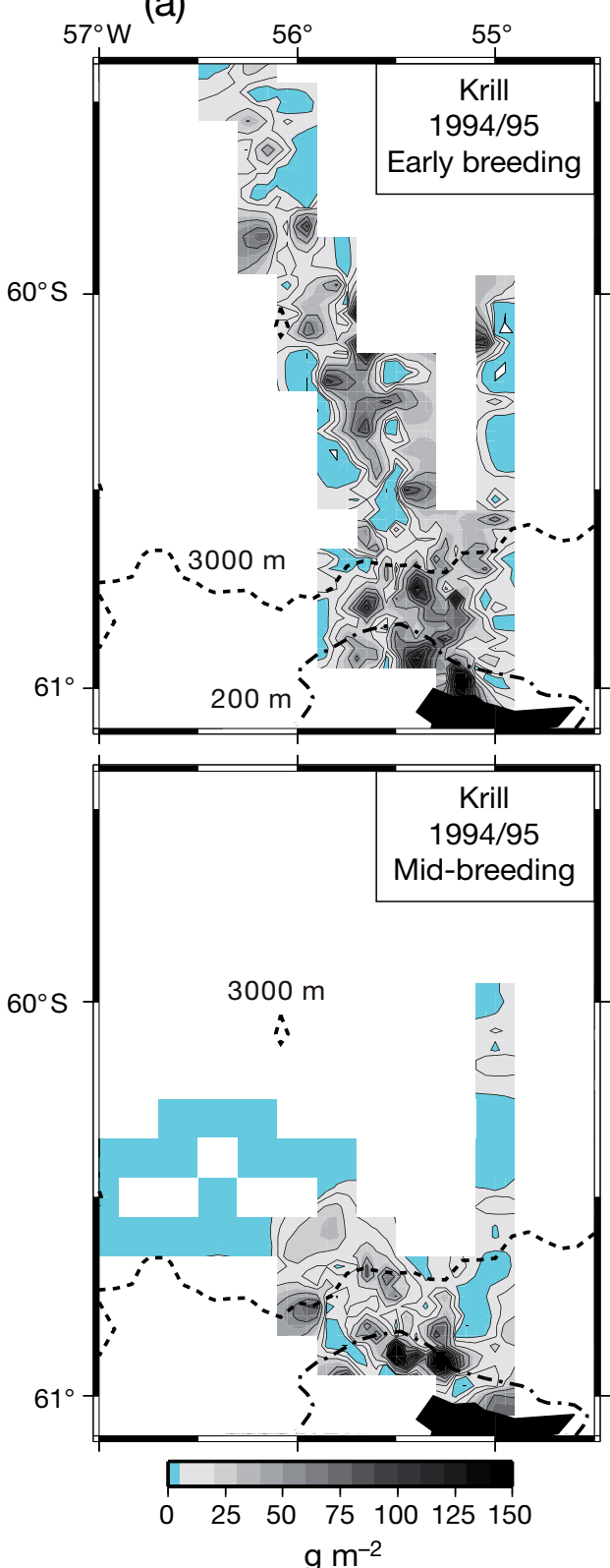

(b)

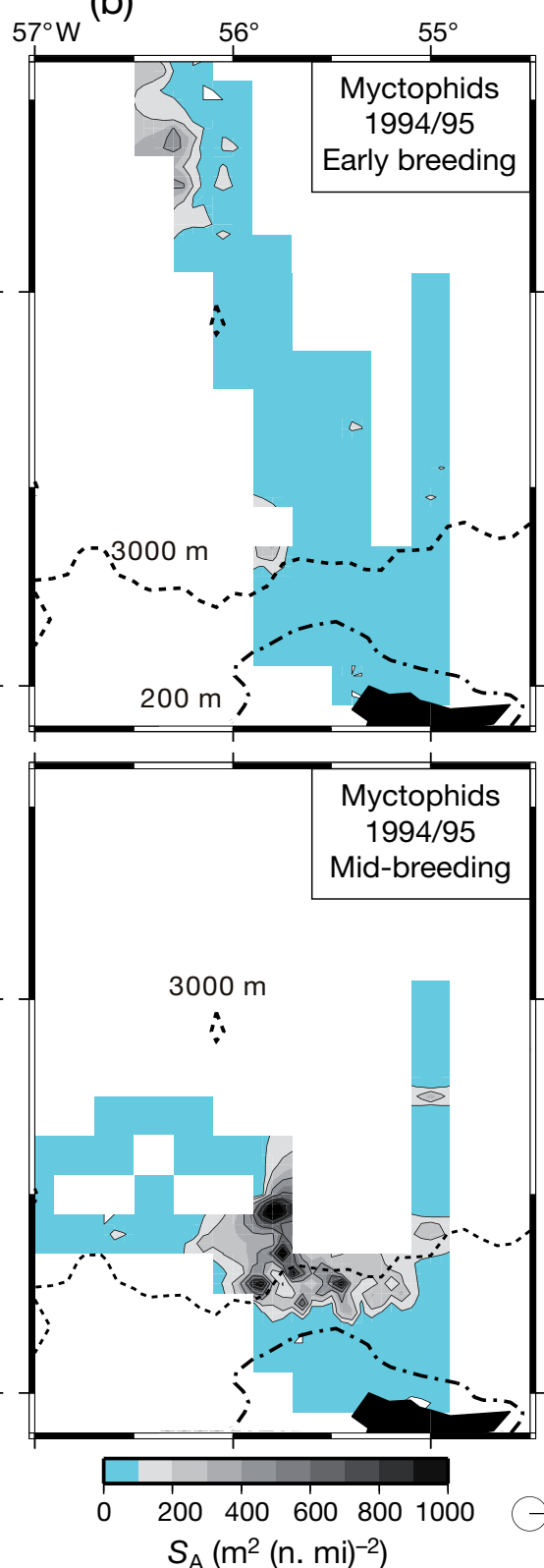

(c)

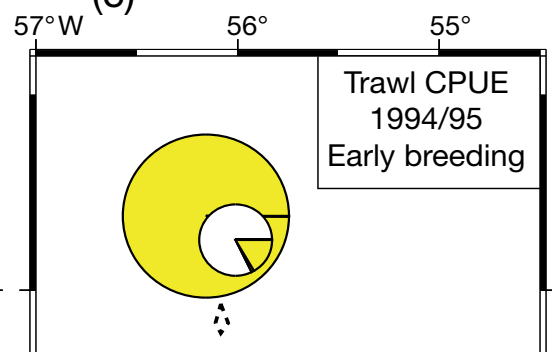

Fig. 3. (a) Krill and (b) myctophid distributions during the early and mid-breeding period, 1994/95. Krill (g m ${ }^{-2}$ ) were measured acoustically in the upper $150 \mathrm{~m}$ depth range at $120 \mathrm{kHz}$, and myctophids $\left(\mathrm{m}^{2} \mathrm{n}\right.$ mile $\mathrm{e}^{-2}$ ) in the 150 to $300 \mathrm{~m}$ depth range at $50 \mathrm{kHz}$. (c) Catch per unit of trawling time (CPUE, $\mathrm{kg} \mathrm{h}^{-1}$ ) distributions of myctophids and krill near surface by trawl net at night during early and mid-breeding period, 1994/95. Krill: Euphausia superba, Ea: Electrona antarctica, Ec: Electrona carlsbergi, Gn: Gymnoscopelus nicholsi; n. mi: nautical mile; $S_{\mathrm{A}}$ : mean backscattering area per square nautical mile

rent (Brandon et al. 2004) corresponded to the southern edge of myctophid concentrations (Fig. 2c). The trawling survey also indicated that the CPUE in this front increased to $155 \mathrm{~kg} \mathrm{~h}^{-1}$ on average (Fig. 3c). Mean densities $\left(\mathrm{m}^{2} \mathrm{n}\right.$ mile $\left.\mathrm{e}^{-2}\right)$ were $4.4,192.4$ and 217.6 for the shelf, slope, and oceanic regions, respectively.

The night-time depth range of myctophids was shallow, up to 50 to $100 \mathrm{~m}$ during the early breeding period (Table 4). Myctophid diurnal vertical migrations became more pronounced in the mid-breeding period, with fish in shallow to near surface $(0$ to $50 \mathrm{~m})$ waters at night (Table 4). Acoustically-detected prey density $\left(S_{\mathrm{A}}\right.$ at $\left.50 \mathrm{KHz}\right)$ also showed the pronounced shallower occurrence of myctophids in the mid-breeding period (Fig. 2c). Furthermore, the mean CPUE of myctophids at night in this period was 2.6 times higher than that of krill in the 0 to $50 \mathrm{~m}$ depth range. This implies a higher abundance of myctophids than krill in the foraging 
(a) Early breeding period 1994/95

Slope, oceanic and far oceanic
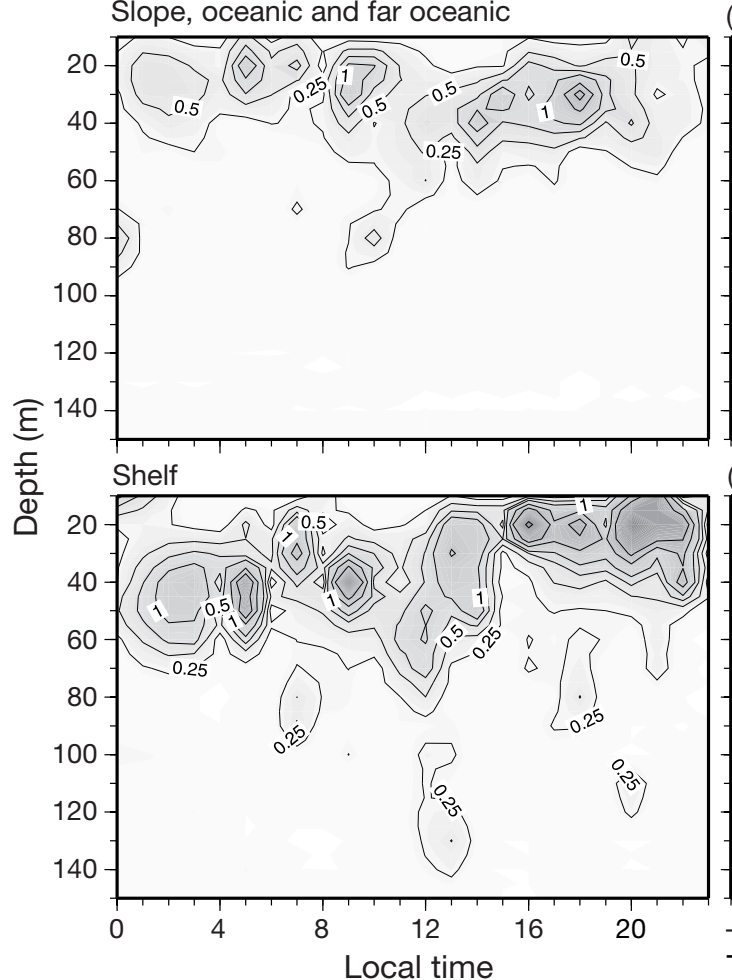

(b) Mid-breeding period 1994/95

Slope and oceanic

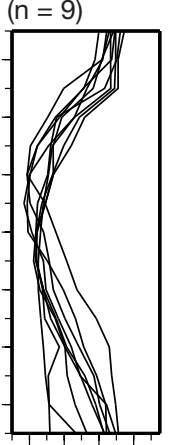

$(\mathrm{n}=2)$

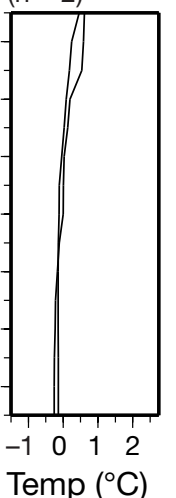

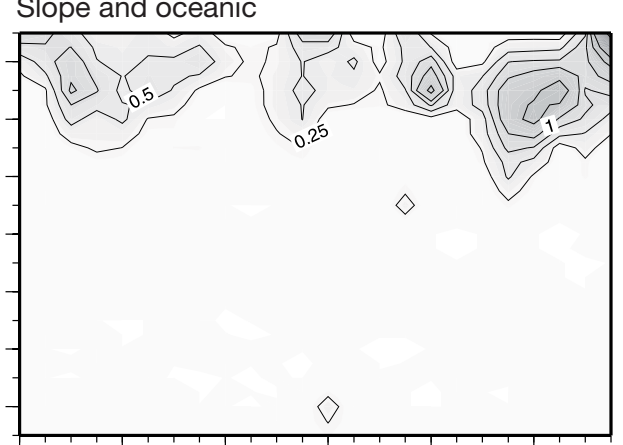

Shelf

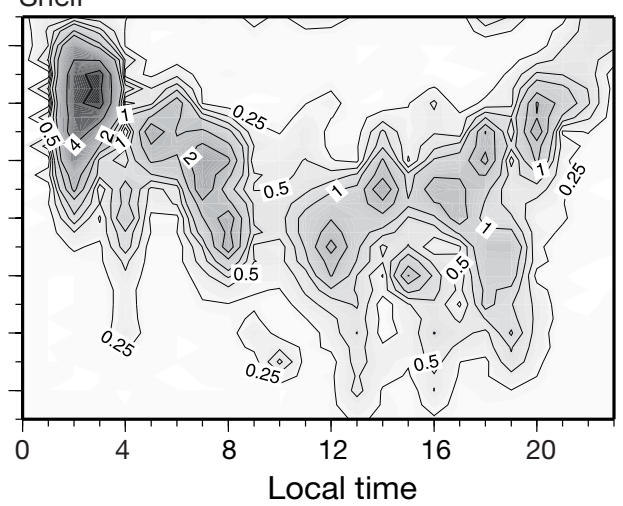

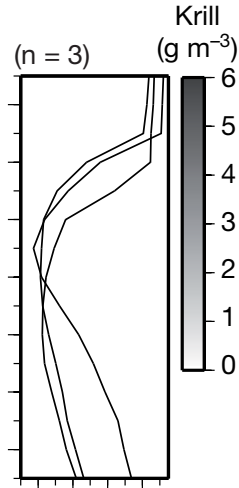

$(n=3)$

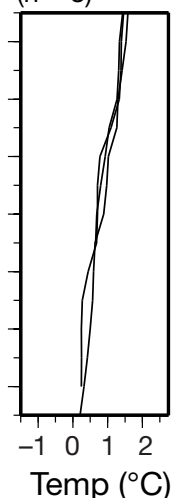

Fig. 4. Diurnal vertical distributions of krill: (a) during the early breeding period in the combined slope + oceanic + far oceanic regions, and shelf region; (b) during the mid-breeding period in the combined slope + oceanic regions and the shelf region (1994/95). Vertical temperature profile is also shown (observed by XBTs). Krill biomass was measured at $120 \mathrm{kHz}$. These panels show averages of all acoustic data collected during the study. Contour interval of krill biomass $\left(\mathrm{g} \mathrm{m}^{-3}\right)$ is 0.25 for mass ranges of $0.00-1.00,0.5$ for $1.0-2.0$ and 2.0 for $2.0-6.0$. n: number of XBT casts

(a) Early breeding period
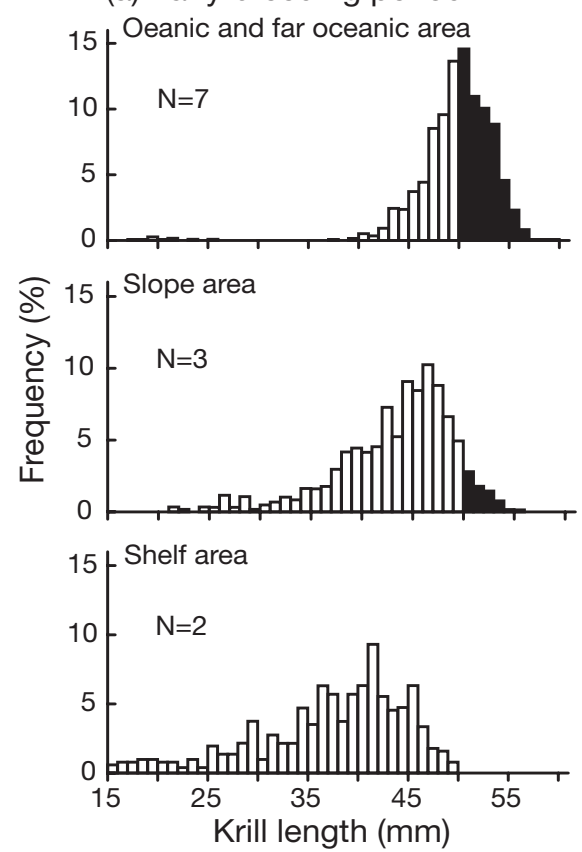

(b) Mid-breeding period
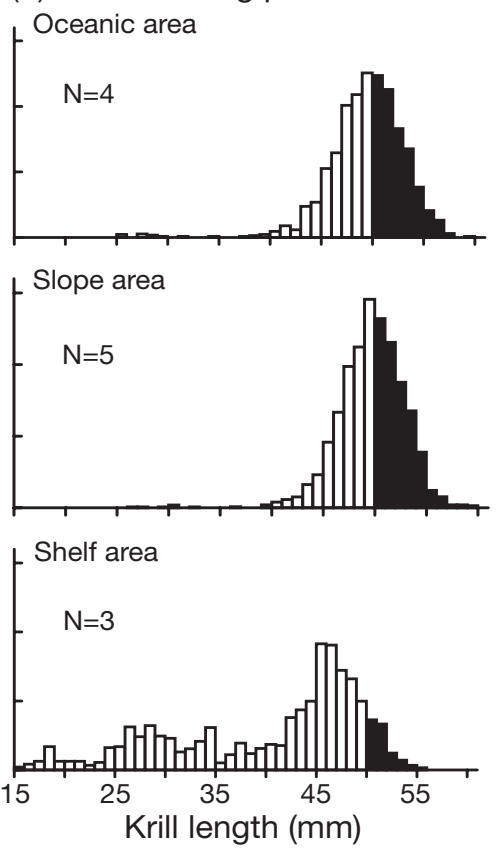

Fig. 5. Average krill size class composition in the oceanic (and far oceanic), slope and shelf regions during the early and mid-breeding period, 1994/95. $\mathrm{N}$ : number of net samples. Black bars indicate size classes $>50 \mathrm{~mm}$

areas, though the number of trawl samples was small.

During the early breeding period, Electrona carlsbergi was dominant in the offshore front, while Gymnoscopelus nicholsi dominated (followed by E. antarctica) in the slope region (Fig. 3c). During the mid-breeding period, E. carlsbergi and G. nicholsi were dominant in the vicinity of the slope front, followed by E. antarctica. Thus, E. carlsbergi penetrated southward to the vicinity of the slope front, $G$. nicholsi and E. antarctica becoming more concentrated in that region at the same time, leading to the high concentration of myctophids near Seal Island.

\section{Foraging areas of Antarctic fur seals}

In the early breeding period of 1994/95, VHF radio and TDR monitoring of fur seal attendance behavior indicated that foraging trip duration was about $5 \mathrm{~d}$ 
$(122.2 \pm 10.9 \mathrm{~h}($ mean $\pm \mathrm{SE})$, range 73.2 to $210.8 \mathrm{~h}, \mathrm{n}=$ 14). The foraging range for one seal tracked by the vessel (Table 5) reached northward of the oceanic front, at least $182 \mathrm{~km}$ from Seal Island (Fig. 6a). The fur seals with PTTs also frequently foraged far from the island, with an average maximum distance of $99 \mathrm{~km}$ (Table 6) and a westward component of up to $85 \mathrm{~km}$. During 1990/91, one foraging trip was tracked in the early breeding period (Table 5). The seal's foraging area extended as far as $240 \mathrm{~km}$ northward from the island (Fig. 6a). Thus, the main feeding areas of the fur seals in this period were in the oceanic and far oceanic regions.

In the mid-breeding period of 1994/ 95, foraging trip duration was shorter, averaging 2 to $3 \mathrm{~d}(60.3 \pm 5.6 \mathrm{~h}$, range 47.7 to $73.6, n=5$ ). The average maximum extent of the foraging range for 2 seals (Table 5) tracked by the vessel was $70 \mathrm{~km}$ from the island (Fig. 6b), not nearly as far as in the early breeding period. The PTT-instrumented seals foraged with an average maximum distance of $52 \mathrm{~km}$ from the island (Table 6). The main foraging area was associated with the slope region and adjacent portions of the oceanic region.

We continued to monitor fur seals with PTTs until the late breeding period in 1994/95. There were significant decreases in the distances swum by seals from Seal Island, indicating that their foraging range contracted as the season progressed (Table 6). By February, the average maximum distance from the island swum by seals was just $28 \mathrm{~km}$, so that the main foraging area was confined to the slope region (Fig. 6c).

Table 4. Catch per towing time (mean \pm SE) for mid-water trawling conducted in offshore foraging area at night in 1994/95. n: number of trawls

\begin{tabular}{|c|c|c|c|c|}
\hline \multirow{3}{*}{$\begin{array}{l}\text { Trawling } \\
\text { depth (m) }\end{array}$} & \multicolumn{4}{|c|}{$\longrightarrow$ CPUE $\left(\mathrm{kg} \mathrm{h}^{-1}{ }\right.$} \\
\hline & \multicolumn{2}{|c|}{ Early breeding period } & \multicolumn{2}{|c|}{ Mid-breeding period } \\
\hline & Krill & Myctophids & Krill & Myctophids \\
\hline $0-50$ & $\begin{array}{c}57.6 \pm 57.6 \\
(\mathrm{n}=2)\end{array}$ & $\begin{array}{c}0.5 \pm 0.5 \\
(\mathrm{n}=2)\end{array}$ & $\begin{array}{c}31.0 \pm 31.0 \\
(\mathrm{n}=3)\end{array}$ & $\begin{array}{c}78.9 \pm 55.1 \\
(\mathrm{n}=3)\end{array}$ \\
\hline $50-100$ & $\begin{array}{c}19.5 \pm 13.2 \\
(\mathrm{n}=4)\end{array}$ & $\begin{array}{c}106.2 \pm 83.7 \\
(\mathrm{n}=4)\end{array}$ & $\begin{array}{c}0.0 \\
(\mathrm{n}=1)\end{array}$ & $\begin{array}{c}382.5 \\
(\mathrm{n}=1)\end{array}$ \\
\hline
\end{tabular}

\section{Diet of Antarctic fur seals}

The fur seal scats in 1990/91 and 1994/95 included krill and myctophids. Krill occurred in the scats throughout the whole breeding period during 1990/91 (38 to $83 \%$ ) (Table 7 ). Although myctophids did not occur in scat during the early breeding period (December), their occurrence increased from the mid- to late breeding period (Table 7).

The single regurgitated sample collected from a fur seal in the mid-breeding period of 1994/95 revealed that the size of krill (47 to $50 \mathrm{~mm}$ mode) consumed was closer to those (48 to $51 \mathrm{~mm}$ mode) sampled in oceanic and slope waters than those (45 to $48 \mathrm{~mm}$ mode) from the shelf region (Fig. 7a). Mature female krill were especially prominant in the regurgitated fur seal sample, as reported previously (Croxall \& Pilcher 1984, Osman et al. 2004).

\section{Foraging areas of chinstrap penguins}

\section{Incubation period}

In the early breeding period of 1994/95, parents took turns incubating their eggs, and foraging trips were of long duration $(75.0 \pm 9.0 \mathrm{~h}$ [mean $\pm \mathrm{SE}]$, range 22.7 to 94, $\mathrm{n}=7$, data from individuals with VHF and TDR). One outbound journey was tracked (Table 5). This penguin went northward far beyond the shelf and slope front, foraging in the oceanic regions (Fig. 8a). The maximum extent of its foraging range was $68 \mathrm{~km}$ from Seal Island. The penguin spent much of its time on 2 icebergs located $49 \mathrm{~km}$ (iceberg A for $5 \mathrm{~h}$ in Fig. 8a) and $68 \mathrm{~km}$ from the island (iceberg B for $54 \mathrm{~h}$ in Fig. 8a) in the oceanic region. Iceberg $\mathrm{B}$ was accompanied by a krill aggregation and relatively high chl a concentration (Fig. 2b). During its stay on and near the icebergs, the penguin occasionally made 30 to 40 min foraging excursions. Another penguin with a transmitter was observed on another iceberg $\left(60^{\circ} 48.0^{\prime} \mathrm{S}, 55^{\circ} 20.6^{\prime} \mathrm{S}\right)$ in the slope region, suggesting that breeding chinstrap penguins may frequently visit oceanic and slope icebergs encountered within the foraging range.

Table 5. Numbers of individuals/trips tracked by the vessel, and the ranges of these foraging trips by stage of the breeding season (early- or mid-season). Maximum distance away from Seal Island is indicated. Mean $\pm \mathrm{SE}$

\begin{tabular}{|c|c|c|c|c|c|c|}
\hline & \multirow{3}{*}{$\begin{array}{c}\text { 1990/91 } \\
\text { Early- } \\
\text { breeding }\end{array}$} & \multirow{2}{*}{\multicolumn{2}{|c|}{ - Seal $\overline{1994 / 95}$}} & \multirow{3}{*}{$\begin{array}{c}\text { 1990/91 } \\
\text { Mid- } \\
\text { breeding } \\
\text { (chick-brooding) }\end{array}$} & \multicolumn{2}{|c|}{ Penguin } \\
\hline & & & & & 199 & $4 / 95$ \\
\hline & & $\begin{array}{c}\text { Early- } \\
\text { breeding }\end{array}$ & $\begin{array}{c}\text { Mid- } \\
\text { breeding }\end{array}$ & & $\begin{array}{c}\text { Early- } \\
\text { breeding } \\
\text { (incubation) }\end{array}$ & $\begin{array}{c}\text { Mid- } \\
\text { breeding } \\
\text { (chick-brooding) }\end{array}$ \\
\hline No. of individuals tracked & 1 & 1 & 2 & 4 & 1 & 3 \\
\hline No. of trips tracked & 1 & 1 & 2 & 6 & 1 & 6 \\
\hline Maximum distance $(\mathrm{km})$ & 230 & 182 & $70 \pm 33$ & $15 \pm 3$ & 68 & $21 \pm 3$ \\
\hline
\end{tabular}




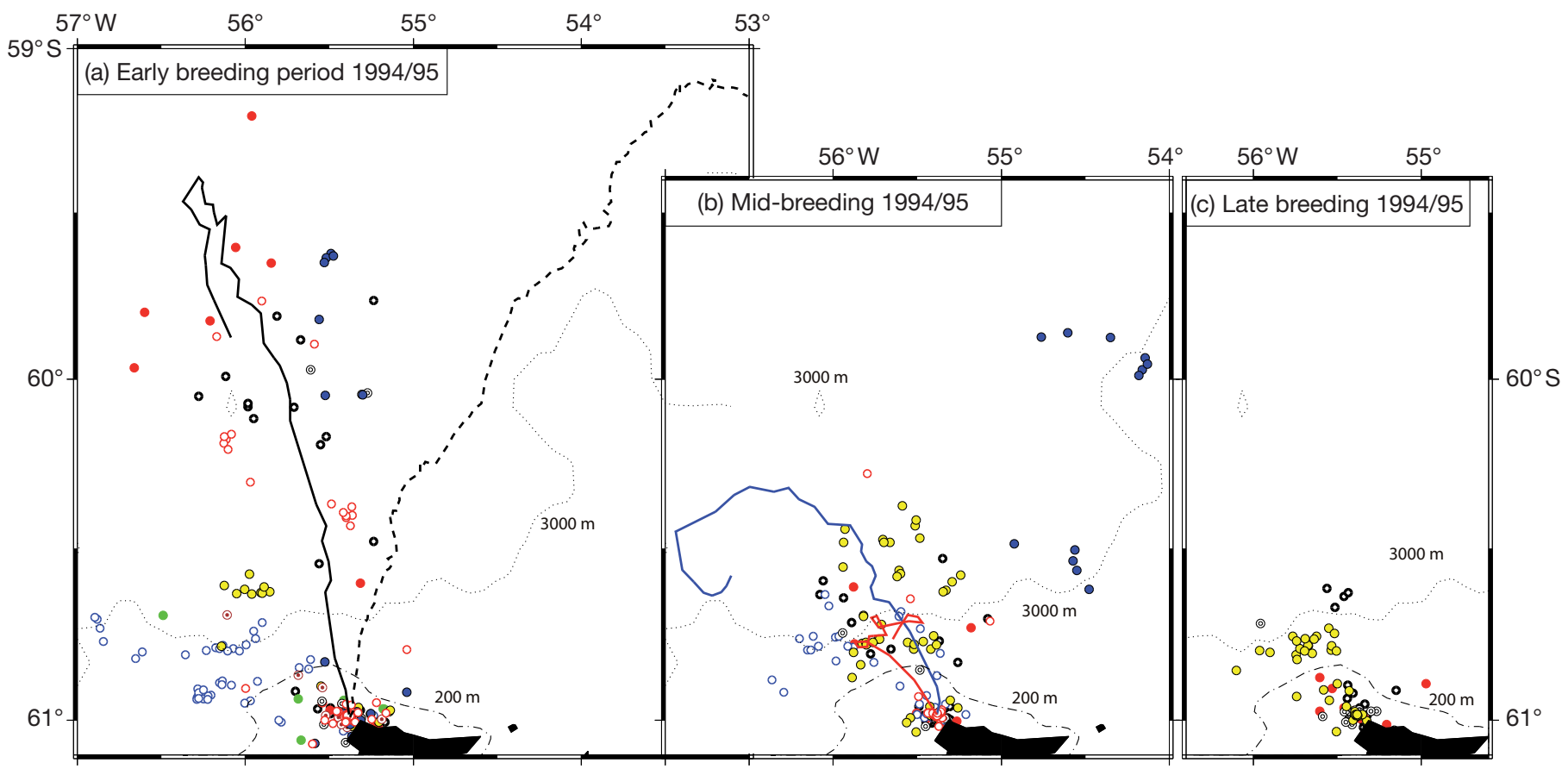

Fig. 6. Temporal changes in locations of fur seals with satellite or radio tags in 1994/95. Different symbols indicate individual fur seals with satellite tags. Solid lines indicate tracks of fur seals (with radio tags) from Seal Island to seal foraging areas in $1994 / 95$. Different colors of solid lines indicate different trips. The broken line represents the track of a fur seal with a radio tag in $1990 / 91$. Numbers of individuals/trips tracked with radio tags are shown in Table 5

\section{Chick brooding period}

In the mid-breeding period of 1994/95, chinstrap penguins were busy feeding their chicks, making short foraging trips during daytime $(6.0 \pm 0.4 \mathrm{~h}$, range 2.1 to $12.5 \mathrm{~h}, \mathrm{n}=34$, data from individuals with VHF and TDR) or longer overnight foraging trips $(11.1 \pm 0.6 \mathrm{~h}$, range 7.2 to 16.1 hours, $\mathrm{n}=16$ ). Tracks to foraging areas were completed for 6 trips (Table 5). Overnight foragers went beyond the shelf edge to the slope (ca. $25 \mathrm{~km}$ from the island), whereas daytime foragers

Table 6. Maximum distances (recorded by PTT) from Seal Island swum by foraging fur seals in different parts of the breeding season. Mean \pm SE. n: number of trips. Kruskal-Wallis test shows significant difference among 3 periods $(\mathrm{p}<0.001)$. Pairwise differences examined using a Mann-Whitney $U$-test with Bonferroni-corrected significance levels of $p=0.05 / 3=0.016^{*}$ and $\mathrm{p}=0.01 / 3=0.003^{* *}($ Sokal $\&$ Rohlf 1997$)$

\begin{tabular}{|c|c|c|c|}
\hline & Early-breeding & Mid-breeding & Late-breeding \\
\hline Distance $(\mathrm{km})$ & $99.3 \pm 9.6$ & $52.2 \pm 5.8$ & $27.7 \pm 3.4$ \\
\hline $\mathrm{n}$ & 20 & 19 & 11 \\
\hline$U$-test & \multicolumn{2}{|c|}{ p-value } & \\
\hline Early vs. mid & \multicolumn{2}{|c|}{$<0.001^{* *}$} & \\
\hline Early vs. late & \multicolumn{2}{|c|}{$<0.001^{* *}$} & \\
\hline Mid vs. late & \multicolumn{2}{|c|}{$0.002^{* *}$} & \\
\hline
\end{tabular}

stayed within the shelf region (ca. $15 \mathrm{~km}$ ) (Fig. 8b). None of the tracked penguins visited icebergs during late January, even though icebergs were present within the foraging range. In 1990/91, tracks to foraging areas were completed for 6 trips during the chickbrooding period (Table 5). As in 1994/95, overnight trips were made to the slope front (ca. $25 \mathrm{~km}$ ) and daytime trips to the shelf ( 7 to $16 \mathrm{~km}$ ) (Fig. 8c).

\section{Diet of chinstrap penguins}

\section{Incubation period}

Penguin prey consumption estimated from partially digested and intact stomach contents comprised krill (82\% of mass and $76 \%$ of caloric value) and myctophids ( $18 \%$ of mass and $24 \%$ of caloric value) during

Table 7. Frequency of occurrence (\%) of krill and myctophids in fur seal scats from early to late breeding period. n: sample size. Samples taken during 1990/91

\begin{tabular}{|lcccc|}
\hline & December & January & February & March \\
\hline $\mathrm{n}$ & 13 & 33 & 26 & 6 \\
Krill & 62 & 61 & 38 & 83 \\
Myctophids & 0 & 61 & 81 & 100 \\
\hline
\end{tabular}


1994/95 (Table 8), suggesting that chinstrap penguins derived some energy from myctophids.

\section{Chick-brooding period}

In both daytime and overnight foragers, krill were predominant in the diet during 1987/88 and 1994/95 (Table 8). Myctophids comprised $<1 \%$ of the estimated diet of daytime foragers by weight, but $21 \%$ in overnight foragers. Myctophids, which constituted $26 \%$ of the energy intake of overnight foragers, appeared to be an important energy source.

The size class compositions of krill eaten by daytime and overnight foragers were compared using diet samples from 1989/90. There was a tendency for overnight foragers to take larger krill and a higher proportion of mature female krill than daytime foragers (Fig. 7b), indicating that the krill were from the slope front and shelf regions. Those taken in daytime, however, were smaller, indicating they were taken from the shelf region.
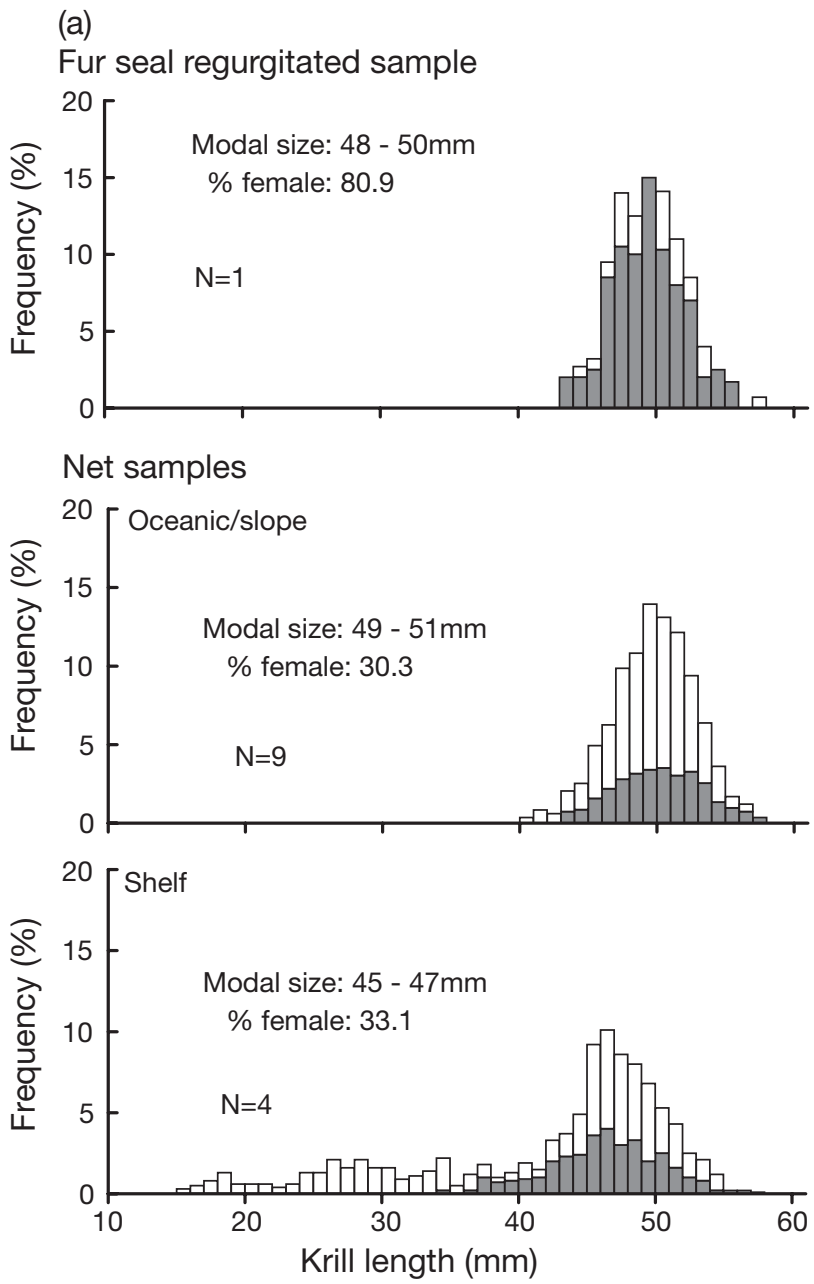

\section{Caloric values of prey}

Caloric values of krill varied among maturity stages (Table 9); mature female krill had a higher value than other stages. Caloric values of myctophid fish were higher than mature female krill; Electrona antarctica had the highest value, followed by E. carlsbergi and Gymnoscopelus nicholsi (Table 9).

\section{Statistical analysis of foraging habitat selection by seals and penguins}

Foraging areas were divided into shelf and offshore (slope and oceanic) habitats for a statistical analysis considering contrasts in prey distribution patterns between them. We compared durations of stay in each habitat between predator types. Data were obtained from shipboard tracking in the mid-breeding (chickbrooding) period in 1990/91 and 1994/95 (Table 10). Four penguins (P1, P2, P5 and P6) were tracked more than once (Table 10). Positive correlation due to

(b)

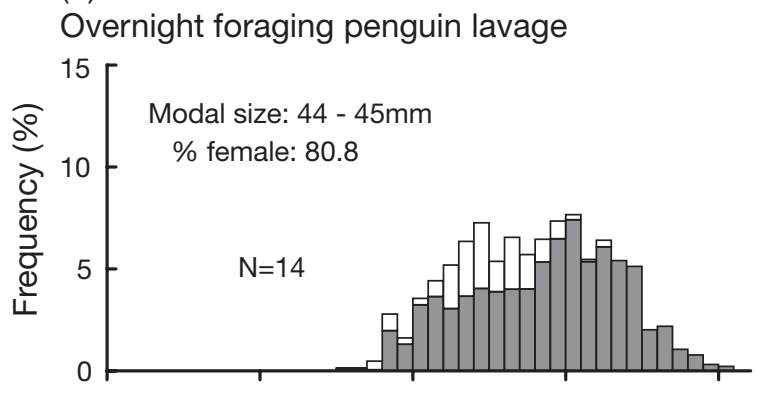

Daytime foraging penguin lavage

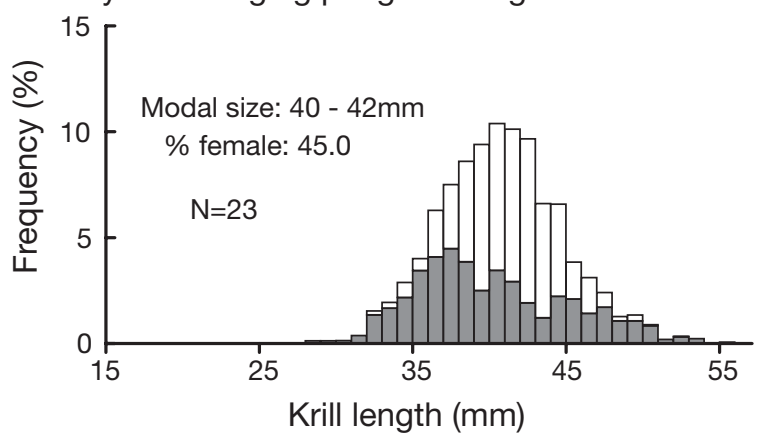

Fig. 7. (a) Krill size class composition from a fur seal regurgitated sample and net samples in the mid-breeding period 1994/95. (b) Krill size class compositions from lavage samples of overnight and daytime foraging chinstrap penguins during the chick-brooding period (mid-breeding period) 1989/90. Shaded bars indicate female krill. N: number of regurgitated, lavage or net samples 


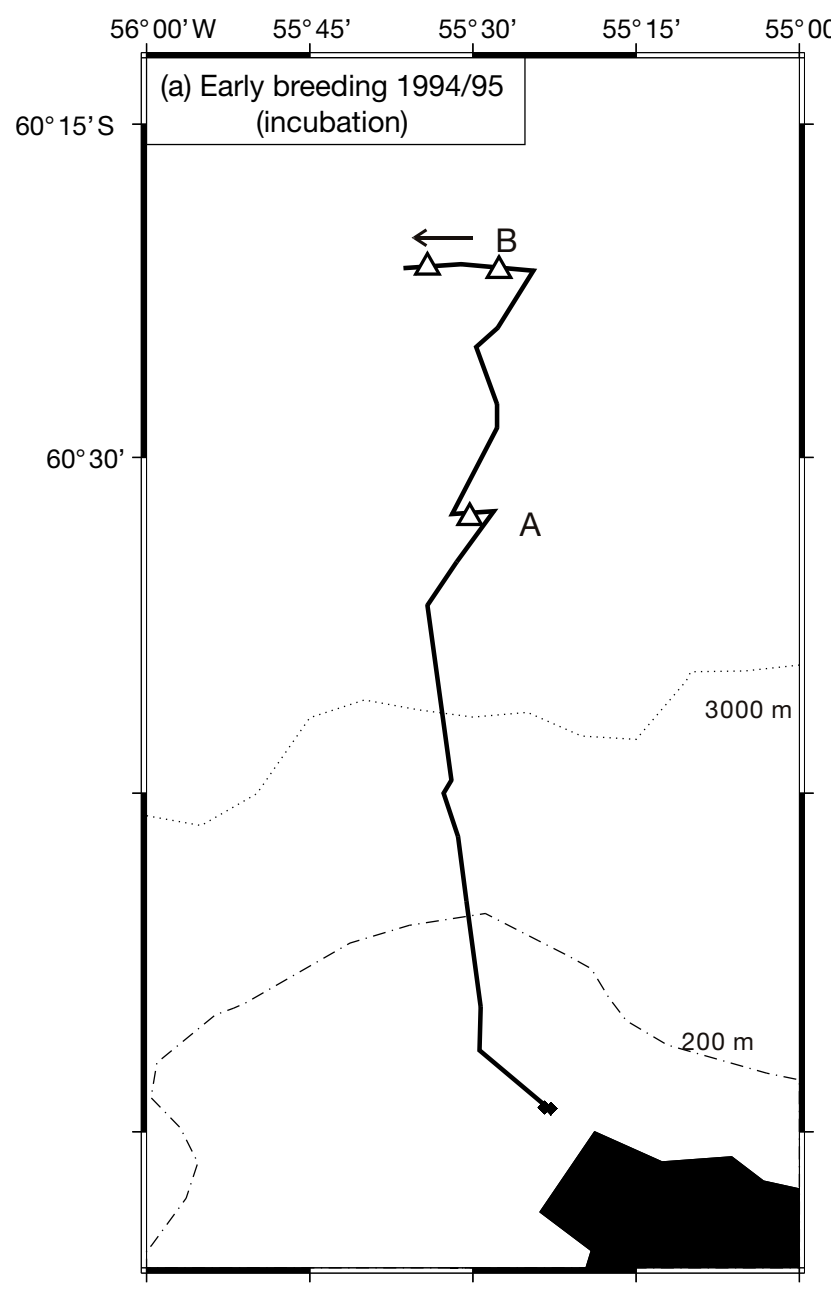

dependency between repeated observations of the same penguins either at night (P2) or during the day (P1 and P6) was taken into account using the random effects model described above. Daytime and overnight trips by the same individuals (P1 and P5) were treated as independent samples, since these trips were of different duration.

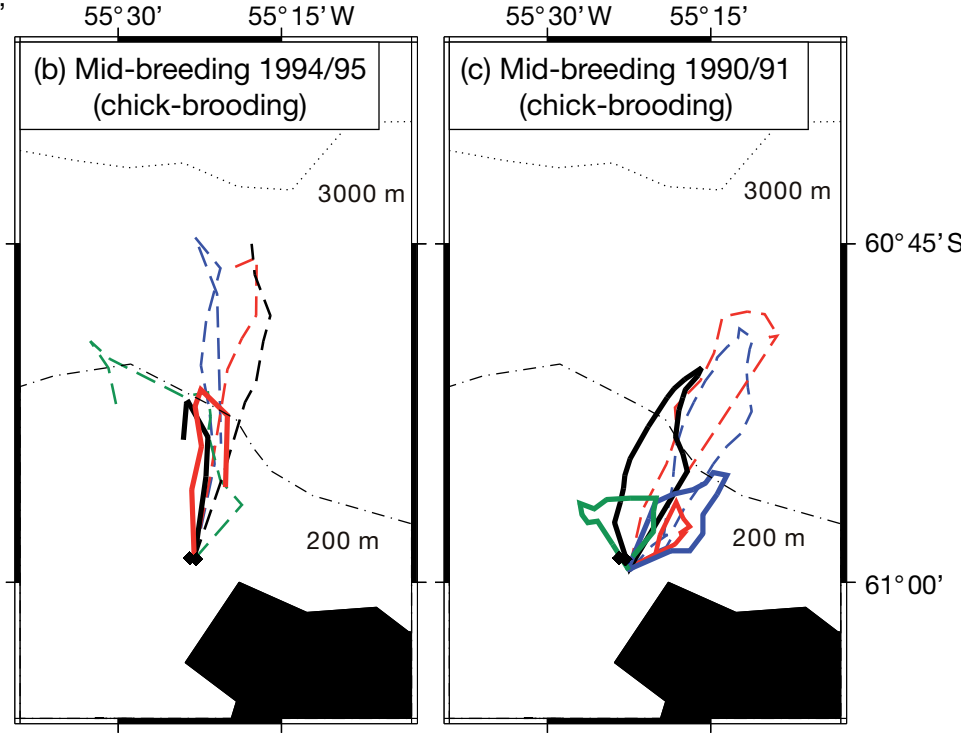

Fig. 8. Chinstrap penguin tracks from Seal Island to foraging areas during (a) incubation in 1994/95, (b) chick-brooding in 1994/95, and (c) chick-brooding in 1990/91. Triangles in (a) indicate icebergs on which the tracked penguin stayed for $5 \mathrm{~h}$ (A) and $54 \mathrm{~h}$ (B) during its foraging trip. Solid and broken lines in (b) and (c) indicate daytime and overnight foraging trips, respectively. Different line colors indicate different trips

Table 8. Average seasonal food composition (\%) as wet weight (wet wt) and energy ( $\mathrm{kJ} \mathrm{g}^{-1}$ wet wt) consumed by chinstrap penguins during the early and mid-breeding period (mean $\pm \mathrm{SE}$ ). N: number of seasons. Incubation data from 1994/95 (number of diet samples = 5). Chick-brood data from 1987/88 (numbers of diet samples for daytime and overnight foragers = 33 and 20 , respectively), 1988/89 (15 and 21), 1989/90 (23 and 14), 1992/93 (20 and 15), 1993/94 (20 and 20) and 1994/95 (2 and 3). Energy calculated from caloric values in Table 9. Other fishes (than those in Table 9) comprised mostly Notolepis coatsi (caloric value

$$
6.2 \mathrm{~kJ} \mathrm{~g}^{-1} \text { wet wt) }
$$

\begin{tabular}{|c|c|c|c|c|c|c|}
\hline & \multirow{2}{*}{\multicolumn{2}{|c|}{ Incubation period }} & \multirow{2}{*}{\multicolumn{4}{|c|}{ Chick-brooding period }} \\
\hline & & & & prager & & prager \\
\hline & $\%$ wet wt & $\%$ energy & $\%$ wet wt & $\%$ energy & $\%$ wet wt & \% energy \\
\hline $\mathrm{N}$ & 1 & 1 & 6 & 6 & 6 & 6 \\
\hline Krill & 81.9 & 76.3 & $99.4 \pm 0.4$ & $99.2 \pm 0.5$ & $74.0 \pm 4.9$ & $67.1 \pm 4.8$ \\
\hline Myctophids & 18.1 & 23.7 & $0.4 \pm 0.4$ & $0.5 \pm 0.5$ & $20.7 \pm 5.5$ & $25.7 \pm 5.7$ \\
\hline Other fish & 0.0 & 0.0 & $0.2 \pm 0.1$ & $0.3 \pm 0.2$ & $5.2 \pm 1.6$ & $7.2 \pm 2.2$ \\
\hline
\end{tabular}


Table 9. Chemical compositions and caloric values (mean $\pm \mathrm{SE}$ ) of krill (by maturity stage) and myctophids. The chitin of krill, which is not digested by predators, is not included. N: sample size; each sample weighed ca. $100 \mathrm{~g}$

\begin{tabular}{|c|c|c|c|c|c|c|c|c|}
\hline Species & $\mathrm{N}$ & Water & Lipid & Protein & $\begin{array}{c}\text { Carbohydrate } \\
\text { (\% wet wt) }\end{array}$ & Ash & Dietary fiber & $\begin{array}{c}\text { Calculated } \\
\text { caloric value } \\
\left(\mathrm{kJ} \mathrm{g}^{-1} \text { wet wt) }\right.\end{array}$ \\
\hline \multicolumn{9}{|l|}{ Euphausia superba } \\
\hline Gravid female (IIID) & 4 & $75.85 \pm 0.38$ & $2.58 \pm 0.08$ & $14.80 \pm 0.15$ & $1.38 \pm 0.36$ & $2.83 \pm 0.03$ & $0.70 \pm 0.04$ & $4.80 \pm 0.05$ \\
\hline Mature male (IIIB) & 4 & $78.89 \pm 0.52$ & $0.93 \pm 0.06$ & $13.93 \pm 0.49$ & $0.10 \pm 0.10$ & $3.45 \pm 0.05$ & $0.68 \pm 0.03$ & $3.73 \pm 0.12$ \\
\hline Less mature female (IIIA) & 2 & $77.65 \pm 1.25$ & $1.50 \pm 0.30$ & $14.45 \pm 0.45$ & $0.60 \pm 0.60$ & $3.10 \pm 0.00$ & $0.70 \pm 0.00$ & $4.16 \pm 0.33$ \\
\hline Less mature male (IIA) & 2 & $77.90 \pm 0.30$ & $1.65 \pm 0.05$ & $13.85 \pm 0.25$ & $0.65 \pm 0.05$ & $3.20 \pm 0.10$ & $0.70 \pm 0.00$ & $4.09 \pm 0.03$ \\
\hline Juvenile & 1 & 78.30 & 1.40 & 14.40 & 0.00 & 3.30 & 0.60 & 4.00 \\
\hline Electrona antarctica & 3 & $71.70 \pm 0.55$ & $14.77 \pm 0.44$ & $11.53 \pm 0.12$ & $0.03 \pm 0.03$ & $1.97 \pm 0.09$ & $0.00 \pm 0.00$ & $8.55 \pm 0.19$ \\
\hline Electrona carlsbergi & 3 & $73.77 \pm 0.66$ & $8.90 \pm 0.12$ & $13.90 \pm 0.32$ & $0.77 \pm 0.07$ & $2.67 \pm 0.19$ & $0.00 \pm 0.00$ & $6.92 \pm 0.13$ \\
\hline Gymnoscopelus nicholsi & 3 & $76.70 \pm 0.71$ & $5.80 \pm 0.32$ & $14.43 \pm 0.30$ & $0.70 \pm 0.17$ & $2.37 \pm 0.03$ & $0.00 \pm 0.00$ & $5.82 \pm 0.22$ \\
\hline
\end{tabular}

Table 10. Foraging ground selection in the mid-breeding period by seals and penguins. The value in each cell is the duration of each individual's stay (as time in hours or \%) in each habitat during its outbound trip until it appeared to be starting on the return leg

\begin{tabular}{|c|c|c|c|c|c|c|c|}
\hline Predator group & Season & Individual & $\begin{array}{l}\text { Shelf } \\
\text { (h) }\end{array}$ & $\begin{array}{l}\text { Slope/oceanic } \\
\text { (h) }\end{array}$ & $\begin{array}{c}\text { Total } \\
\text { (h) }\end{array}$ & $\begin{array}{l}\text { Shelf } \\
(\%)\end{array}$ & $\begin{array}{c}\text { Slope/oceanic } \\
(\%)\end{array}$ \\
\hline \multirow[t]{2}{*}{ Seals } & $1994 / 95$ & S 1 & 2.5 & 24.0 & 26.5 & 9.4 & 90.6 \\
\hline & $1994 / 95$ & S 2 & 2.1 & 25.3 & 27.4 & 7.7 & 92.3 \\
\hline \multicolumn{8}{|c|}{ Foraging penguins } \\
\hline \multirow[t]{6}{*}{ Overnight } & $1994 / 95$ & P 1 & 4.8 & 3.8 & 8.6 & 55.8 & 44.2 \\
\hline & $1994 / 95$ & P 2 & 2.5 & 4.0 & 6.5 & 38.5 & 61.5 \\
\hline & $1994 / 95$ & P 2 & 1.1 & 6.1 & 7.2 & 15.3 & 84.7 \\
\hline & $1994 / 95$ & P 3 & 2.6 & 4.9 & 7.5 & 34.7 & 65.3 \\
\hline & 1990/91 & P 4 & 3.1 & 3.8 & 6.9 & 44.9 & 55.1 \\
\hline & 1990/91 & P 5 & 6.0 & 3.5 & 9.5 & 63.2 & 36.8 \\
\hline \multirow[t]{6}{*}{ Daytime } & $1994 / 95$ & P 1 & 4.8 & 1.0 & 5.8 & 82.8 & 17.2 \\
\hline & $1994 / 95$ & P 1 & 3.9 & 0.0 & 3.9 & 100.0 & 0.0 \\
\hline & 1990/91 & P 6 & 4.0 & 1.1 & 5.1 & 78.4 & 21.6 \\
\hline & $1990 / 91$ & P 6 & 3.4 & 0.0 & 3.4 & 100.0 & 0.0 \\
\hline & 1990/91 & P 5 & 2.8 & 0.3 & 3.1 & 90.3 & 9.7 \\
\hline & 1990/91 & P 7 & 4.5 & 0.0 & 4.5 & 100.0 & 0.0 \\
\hline
\end{tabular}

seals tended to choose the offshore habitat as the most suitable region for foraging, whereas overnight foraging penguins chose the offshore and shelf habitats with approximately equal frequency, while daytime foraging penguins were biased toward the shelf habitat. The fact that the confidence intervals did not overlap lends strength to the evidence for distinct habitat selection behaviors (Table 11). Even though only 2 fur seals were tracked directly from the ship, the tendency for fur seals to select the offshore (slope and oceanic) foraging ground was also supported by the satellite tracking results.

Two conventional tests of the residuals from equation (4) (Conover 1999) showed no significant deviations from normal distributions (Kolmogorov-Smirnov: $\mathrm{p}=0.9157$; Shapiro-Wilk: $\mathrm{p}=0.4809$ ).

\section{DISCUSSION}

\section{Advantages of each foraging region}

There were differences in prey availability between the shelf, and the slope and oceanic (including far oceanic) regions. The shelf region had a higher krill density $\left(63 \mathrm{~g} \mathrm{~m}^{-2}\right.$ and $76 \mathrm{~g} \mathrm{~m}^{-2}$ in early and mid-breeding seasons, respectively) than the slope and oceanic regions $\left(23 \mathrm{~g} \mathrm{~m}^{-2}\right.$ and $\left.17 \mathrm{~g} \mathrm{~m}^{-2}\right)$. Prey in the shelf region was also much closer to the island breeding colonies. On the other hand, the slope and oceanic regions had the advantage in prey type, which could influence the foraging efficiency of predators. Myctophids and gravid krill, which were dominant in the slope and oceanic regions, were richer in energy content than 
Table 11. Habitat selection index estimates. Habitat selection index for shelf region $=1-$ (Habitat selection index for offshore [slope/oceanic] region). Lower (upper) $2.5 \%$ denotes the lower (upper) bound of logit-based confidence interval

\begin{tabular}{|lcccc|}
\hline Predator group & $\begin{array}{c}\text { Habitat selection } \\
\text { index estimate for } \\
\text { offshore region }\end{array}$ & SE & $\begin{array}{c}\text { Lower } \\
2.5 \%\end{array}$ & $\begin{array}{c}\text { Upper } \\
2.5 \%\end{array}$ \\
\hline Seals & 0.915 & 0.012 & 0.887 & 0.936 \\
$\begin{array}{l}\text { Overnight foraging penguins } \\
\text { Daytime foraging penguins }\end{array}$ & 0.564 & 0.049 & 0.467 & 0.657 \\
& 0.089 & 0.050 & 0.029 & 0.247 \\
\hline
\end{tabular}

the early breeding period (December; Table 7), because these fishes were available only in an area remote from the island at that time; fish otoliths may have been defecated before seals returned to the island. Casaux et al. (1998) also reported that the diets of fur seals during the breeding season were dominated by myctophids (46\% in mass) and krill (43\%) at Nelson Island, South Shetland Islands. Furthermore, dive depth ranges of fur seals at Seal Island were consistently shallow $(<50 \mathrm{~m})$ during the day, whereas

less mature adult krill, which were dominant in the shelf region. Caloric values per unit wet weight of myctophids and gravid krill were 1.4 to 2.1 and 1.2 times higher (Table 9), respectively, than those of less mature adult krill, and 22 to 82 and 1.7 times, respectively, the caloric value per individual. Furthermore, myctophids may be easy for predators to detect because of their large photophores, and these fishes may occur in dense aggregations.

The slope and oceanic regions were also characterized by a shallower (< ca. $40 \mathrm{~m}$ ) distribution of krill throughout the day during the early and mid-breeding periods (Fig. 4), which was probably caused by the strong and shallow (ca. $30 \mathrm{~m}$ depth) thermocline. In contrast, in the shelf region, which had little stratification (no thermocline) in the water column (Fig. 4), krill undertook diel vertical migrations during the midbreeding period. The diurnal descent (40 to $140 \mathrm{~m}$ ) of krill in the shelf region may be a result of predation pressure (Gliwicz 1986, Frost \& Bollens 1992) by daytime foraging penguins that foraged intensively during that period.

Thus, these central-place foragers were faced with a trade-off. The shelf region had the advantages of high krill abundance and proximity to breeding colonies, while the slope and oceanic regions had the advantages of the presence of energy-rich bioluminescing myctophid fish near the surface at night, the availability of energy-rich gravid krill and the shallow distribution of krill in the water column.

\section{Foraging of Antarctic fur seals}

Antarctic fur seals foraged as far north as the oceanic front and the oceanic region during the early breeding period, and foraged in the slope and oceanic regions during the mid-breeding period (Fig. 6). Fur seals fed on krill, and with increasing frequency on myctophids, which increased in abundance in the slope and oceanic regions from the early to mid-breeding period. Myctophids were absent from fur seal scats during they were variable ( 5 to $100 \mathrm{~m}$ ) at night (Boveng et al. 1991, this study). Their nighttime deep diving to depths where myctophids were present, despite the presence of krill in the upper $40 \mathrm{~m}$, suggests that they may have chosen myctophids over krill. Even though the sample size for krill was very small, fur seals were considered to feed mainly on larger gravid krill females in the slope front and oceanic regions, rather than on mid-sized individuals in the shelf region. Some authors have also reported that krill eaten by Antarctic fur seals off the South Shetland Islands and South Georgia were exclusively mature (including gravid) females (Croxall \& Pilcher 1984, Osman et al. 2004).

Why did fur seals not feed in the shelf region, which has more abundant krill and is closer to the breeding site? Krill in the shelf region comprised energy-poor, mid-sized individuals. These could be less profitable for fur seals to pursue and capture, especially in the mid-breeding period, when the krill moved to deeper

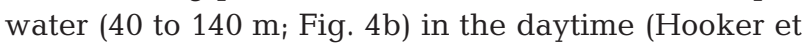
al. 2002). Costa (1991) suggested that, due to the small size and low energy value of krill, hunting individual krill is only efficient for fur seals when krill are near the surface. Antarctic fur seals off South Georgia capture krill mostly from shallow (upper $30 \mathrm{~m}$ ) depths (Croxall et al. 1985, Boyd 1996). In the slope and oceanic regions, on the other hand, gravid female krill occurred not only near the surface throughout the day, but also tended to aggregate near the thermocline (ca. $30 \mathrm{~m}$ depth), which may enhance predictability of their distribution and facilitate location by seals. The mean diving depth of fur seals off Seal Island was 20 to $30 \mathrm{~m}$ during the day, which corresponded to the thermocline depth in the study region (Boveng et al. 1991, this study). Hunt et al. (1990) suggested that the concentration of prey in the vertical dimension may be important for efficient foraging by predators, based on an observation that planktivorous least auklets preferred to forage where prey was concentrated at the shallow thermocline.

The cost to fur seals in travelling extended distances to the slope and oceanic regions can be estimated 
using the value of minimum transport cost $\left(2.3 \mathrm{~J} \mathrm{~m}^{-1}\right.$ $\mathrm{kg}^{-1}$ ) for adult female harbor seals (Davis et al. 1985). Given that the daily fur seal travel distance is ca. $85 \mathrm{~km}$ on average, based on our shipboard study, the daily energy cost for a female seal to travel this distance would be $217 \mathrm{~kJ} \mathrm{~kg}^{-1}$ at $90 \%$ assimilation efficiency (Miller 1978). This travel cost is $22 \%$ of daily field metabolic rate of a female Antarctic fur seal at sea at sea (988.5 kJ kg ${ }^{-1} \mathrm{~d}^{-1}$, Croll \& Tershy 1998). Since the energy-rich myctophids and gravid krill in the slope and oceanic regions have 40 to $110 \%$ and $20 \%$ more caloric value per unit wet weight than less mature adult krill in the shelf region, respectively, an increased consumption of energy-rich prey in the slope and oceanic regions could offset the increased costs of traveling associated with reaching offshore predator feeding grounds. Thus, overall foraging efficiency for lactating fur seals in the slope and oceanic regions may be superior to that in the shelf region.

\section{Foraging of chinstrap penguins}

Incubation period

When chinstrap penguins were not constrained by the need to provision offspring, as in the case of the single bird that we tracked, foraging took place largely in the oceanic region, probably mainly on large-sized krill and occasionally on myctophids. This bird stayed on an oceanic iceberg (which was surrounded by mature krill) for $54 \mathrm{~h}$. The TDR data from this individual indicated that it entered the water every few hours and repeatedly dove to depths (26 m average) at which krill occurred, suggesting that the iceberg was used as both a resting and a foraging platform. Association with icebergs accompanied by krill could be an efficient foraging strategy, since penguins using the icebergs would not have to search far for krill. Even if such icebergs are not available, the oceanic region with larger, higher energy-content krill could be more advantageous than the shelf region. Larger samples of penguins tracked during incubation will be required to confirm this foraging strategy in association with icebergs. The importance of icebergs as foraging platforms for seabirds in open waters was also suggested by Ainley et al. (1986).

Long distance foraging is common during the incubation period in other seabirds. Macaroni penguins Eudyptes chrysolophus on South Georgia foraged over a much larger range (376 to $572 \mathrm{~km}$ on average from the breeding site) during their incubation trips than on brooding trips over the continental shelf $(62 \mathrm{~km}$ on average) (Barlow \& Croxall 2002). Their incubationperiod foraging range included the Polar Frontal Zone, suggesting that they target the distant, but potentially highly productive area, where diverse prey, including Antarctic krill and fish, may be found. Wandering albatrosses Diomedea exulans off the Crozet Archipelago also traveled 3.7 times farther and were at sea 3.2 times longer during incubation than during brooding (Shaffer et al. 2003). During the incubation period, albatrosses foraged in pelagic waters where they could use favorable winds to achieve low flight costs, whereas during the brooding period they foraged on the continental shelf-slope close to the islands where they could not use wind as effectively for travel, which could increase foraging costs (Weimerskirch et al. 2000). Since foraging costs during incubation were significantly lower than during brooding, incubating albatrosses appear to maximize foraging efficiency by maximizing time at sea and minimizing the energy costs of foraging (Shaffer et al. 2003). In our study, incubating chinstrap penguins may have maximized foraging efficiency by exploiting distant but potentially profitable slope and oceanic regions (like Macaroni penguins) and by simultaneously decreasing foraging effort (like wandering albatrosses) by using icebergs and exploiting krill in shallow water.

\section{Chick brooding period}

When constrained by the need to provision offspring at short intervals, chinstrap penguins traveled shorter distances from their breeding colonies. They foraged in 2 modes: daytime and overnight (Jansen et al. 1998). Daytime foragers fed on krill in the shelf region, while overnight foragers fed on myctophids in the slope region and krill in the slope and shelf regions, raising the question as to why they changed their foraging areas between day and night.

Feeding efficiencies in the slope and shelf regions can be evaluated from the respective prey densities within the penguins' diving depth range. We compared prey (krill and myctophids) density between the 2 regions using $S_{\mathrm{A}}$ measurements at $50 \mathrm{kHz}$, which could detect both krill and myctophids in both day (04:00 to $20: 00 \mathrm{~h})$ and night $(21: 00$ to $03: 00 \mathrm{~h})$. In the daytime, the average diving depth of chinstrap penguins was $39 \mathrm{~m}$ in the shelf region and the average prey density was $22 \mathrm{~m}^{2} \mathrm{n}$ mile $\mathrm{e}^{-2}$ at that depth (Fig. 9). However, an equivalent prey density was available at a shallower depth $(25 \mathrm{~m})$ in the slope region. This suggests that penguins stayed on the shelf, even though they had to dive deeper for prey, probably so as to shorten their trip durations, thereby increasing the frequency of chick provisioning. At night, their average diving depth was $20 \mathrm{~m}$ in the slope region, and average prey density was $85 \mathrm{~m}^{2} \mathrm{n}$ mile $\mathrm{e}^{-2}$ at that depth. How- 


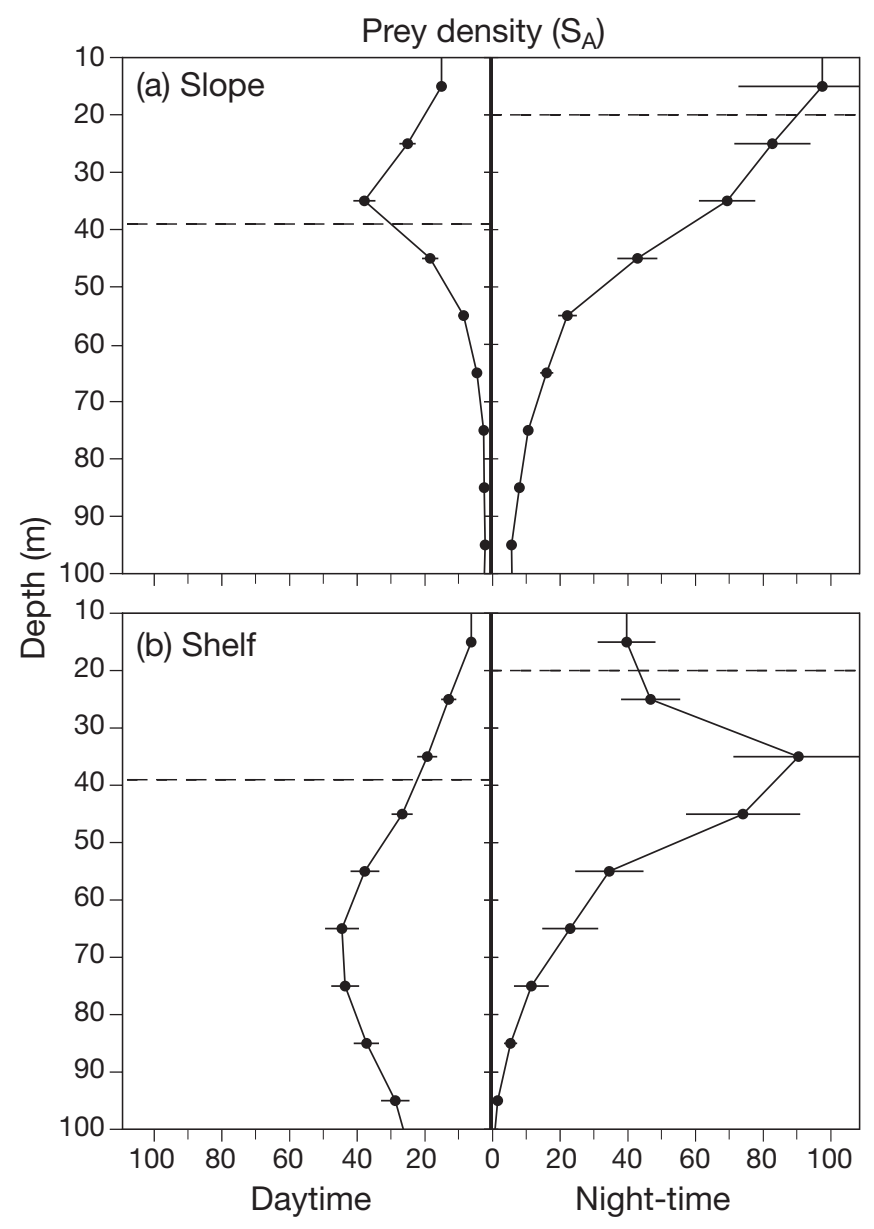

Fig. 9. Prey density in relation to depth in the daytime and at night in the slope (a) and shelf (b) regions, during the midbreeding (chick-brooding) period of 1994/95. Prey (krill and myctophids) density $\left(S_{\mathrm{A}}\right.$ mean $\left.\pm \mathrm{SE}\right)$ is shown as $\mathrm{m}^{2} \mathrm{n}$ mile ${ }^{-2}$ at $50 \mathrm{kHz}$, by $10 \mathrm{~m}$ depth intervals and integrated horizontally every 200 to $500 \mathrm{~m}$ in 1994/95. Broken lines indicate average diving depths of chinstrap penguins in 1994/95. These average diving depths were calculated from 9032 dives by 9 individuals, using the method of Bengtson et al. (1993)

ever, prey of equivalent density was available in deeper water $(35 \mathrm{~m})$ on the shelf. This suggests that penguins extended foraging distances to the slope, even though they might obtain similar prey density by diving deeper on the shelf, probably so as to make good use of their periods of poor visibility at night. Jansen et al. (1998) indicated that reduced light could limit penguin ability, not only to capture prey, but also to negotiate the complex and hazardous coastline of Seal Island safely (i.e. heavy surf along rocky bluffs and shoreline). Hence, even if overnight foragers finish foraging earlier, they have to wait until dawn before returning to their nests. In other words, they do not have to hurry back to their breeding sites. Therefore, overnight foragers may have good reason to visit the distant region, i.e. the slope, where prey was relatively energy-rich and the density near the surface was up to 2.5-fold greater than in the shelf region (Fig. 9). Thus, the difference in foraging range between daytime and overnight foragers also suggests that predators with less severe time constraints were likely to forage in distant but potentially more profitable feeding grounds.

The travel cost for chinstraps between the shelf and slope can be estimated using the value of minimum transport cost $\left(3.7 \mathrm{~J} \mathrm{~m}^{-1} \mathrm{~kg}^{-1}\right.$ ) for this species (Culik et al. 1994). Given that the distance between the 2 regions is ca. $10 \mathrm{~km}$, the energy cost for a penguin to travel both ways $(20 \mathrm{~km})$ would be $100.0 \mathrm{~kJ} \mathrm{~kg}^{-1}$ at $74 \%$ assimilation efficiency (Davis et al. 1989). This travel cost is $9.4 \%$ of the daily field metabolic rate (1068.4 kJ kg $\mathrm{kg}^{-1}$, Croll \& Tershy 1998) of an adult that spends $50 \%$ of its time at sea and $50 \%$ resting at the colony, suggesting that the extra travel cost between the 2 regions is not expensive in terms of daily total energy requirement.

Recent studies suggest that procellariiform seabirds, including albatrosses and shearwaters, employ bimodal and unimodal foraging strategies, depending on nearcolony resource availability during the chick-brooding period (e.g. Catard et al. 2000, Waugh et al. 2000, Baduini \& Hyrenbach 2003). When near-colony resources are less productive, parents use a bimodal foraging strategy that alternates multiple short foraging trips in near-colony areas for chick provisioning, with longer trips to more productive distant areas for selfprovisioning. In this case, parents lose body mass in short near-colony trips, but chicks gain mass rapidly, while parents restore body mass at the expense of lower feeding rate for chicks in long trips (Weimerskirch 1998, Weimerskirch \& Cherel 1998). The decision to engage in a short or a long foraging trip is influenced by parent body condition just prior to leaving the colony, rather than by the condition of the chicks. On the other hand, when near-colony resources are productive, parents use unimodal foraging trips (based on near-colony productivity only) that provision for themselves and chicks (Waugh et al. 2000, Baduini \& Hyrenbach 2003). In this case, longer foraging trips are not required to restore parent body mass. We do not regard overnight (long) foraging trips of chinstrap penguins during the chick-brooding period as a means of restoring parent body mass, but simply as a consequence of coordinating a foraging routine between mates to maintain the timely delivery of food to chicks (Jansen 1996, Jansen et al. 2002). This is because, during the crèche period, when parents are released from attending chicks and accordingly begin foraging more independently of one another, most forage in the daytime only, suggesting that they do not prefer foraging at night, due to visual constraints (Jansen 1996, Jansen et al. 2002). A related point is that chinstrap penguins may 
have a larger safety margin in body mass for breeding than flying procellariiform birds that reduce traveling (flight) efficiency with additional accumulation of body mass. Hence, penguins may be less likely to reach the lower threshold mass at which they need to take long foraging trips to restore their body mass. In conclusion, the bimodal (long/short) foraging pattern of the chinstrap penguins may not result from a conflict between self-feeding and chick feeding, but from a difference in foraging time constraints between day and night.

\section{CONCLUSION}

Despite the occurrence of high krill concentrations in the close-shelf region, only brooding penguins foraged there, whereas lactating fur seals and incubating penguins foraged in the distant slope and oceanic regions. Foraging profitability may not necessarily be associated exclusively with high density of krill, but rather with its shallow distribution, which may enhance capture rate for predators. Moreover, the availability of energy-rich prey such as myctophid fish and gravid krill is also likely of importance. Thus, we suggest that, for the purpose of maximizing energy intake rate, lactating Antarctic fur seals and incubating chinstrap penguins (i.e. energy-maximizers) forage in the distant, but potentially more profitable slope and oceanic regions, while brooding penguins (i.e. time-minimizers) forage in the closer but potentially less profitable shelf region. Thus, time and energy constraints derived from different provisioning strategies may result in these predators using different areas, and as a result, central-place foragers may sometimes use foraging habitats that are sub-optimal in terms of the quality of prey availability.

Acknowledgements. We thank A. Takahashi, Y. Watanuki, H. Watanabe and Y. Mori for critical reading of the manuscript. Helpful comments on statistics were provided by J. Ver Hoef. We are grateful to Y. Naito, M. Fukuchi, K. Mahapatra, M. Kiyota and S. Yonezaki for their useful discussions. A. Miura helped us with penguin diet analysis and N. Baba with the satellite tracking. K. Segawa kindly provided sea bottom contour data. Our sincere thanks are due to the captains, officers and crews of the RV 'Kaiyo Maru' for their assistance during the cruises.

\section{LITERATURE CITED}

Aebischer NJ, Robertson PA, Kenward RE (1993) Compositional analysis of habitat use from animal radio-tracking data. Ecology 74:1313-1325

Ainley DG, Fraser WR, Sullivan CW, Torres JJ, Hopkins TL, Smith WO (1986) Antarctic mesopelagic micronekton: evidence from seabirds that pack ice affects community structure. Science 232:847-849

Akaike H (1973) Information theory and an extension of the maximum likelihood principle. In: Petran BN, Csaaki F (eds) International symposium on information theory. Akadeemiai Kiadi, Budapest, p 267-281

Baduini CL, Hyrenbach KD (2003) Biogeography of procellariiform foraging strategies: does ocean productivity influence provisioning? Mar Ornithol 31:101-112

Barlow KE, Croxall JP (2002) Seasonal and interannual variation in foraging range and habitat of macaroni penguins Eudyptes chrysolophus at South Georgia. Mar Ecol Prog Ser 232:291-304

Bengtson JL, Croll DA, Goebel ME (1993) Diving behavior of chinstrap penguins at Seal Island. Antarct Sci 5:9-15

Bingham RL, Brennan LA (2004) Comparison of type I error rates for statistical analyses of resource selection. J Wildl Manage 68:206-212

Boveng PL, Bengtson JL, Goebel MF (1991) Antarctic fur seal foraging patterns at Seal Island, South Shetland Islands, Antarctica, during austral summer 1990-1991. Antarct J US 26:215-216

Boyd IL (1996) Temporal scales of foraging in a marine predator. Ecology 77:426-434

Brandon MA, Naganobu M, Demer DA, Chernyshkov P and 6 others (2004) Physical oceanography in the Scotia Sea during the CCAMLR 2000 survey, austral summer 2000. Deep-Sea Res II 51:1301-1321

Burnham KP, Anderson DR (1998) Model selection and inference: a practical information-theoretic approach. Springer-Verlag, New York

Casaux R, Baroni A, Carlini A (1998) The diet of the Antarctic fur seal Arctocephalus gazella at Harmony Point, Nelson Island, the South Shetland Islands. Polar Biol 20:424-428

Catard A, Weimerskirch H, Cherel Y (2000) Exploitation of distant Antarctic waters and close shelf-break waters by white-chinned petrels rearing chicks. Mar Ecol Prog Ser 194:249-261

Conover WJ (1999) Practical nonparametric statistics, 3rd edn. John Wiley \& Sons, New York

Costa DP (1991) Reproductive and foraging energetics of high latitude penguins, albatrosses and pinnipeds: implications for life history patterns. Am Zool 31:111-130

Croll DA, Tershy BR (1998) Penguins, fur seals, and fishing: prey requirements and potential competition in the South Shetland Islands, Antarctica. Polar Biol 19:365-374

Croxall JP, Pilcher MN (1984) Characteristics of krill Euphausia superba eaten by Antarctic fur seals Arctocephalus gazelle at South Georgia. Br Antarct Surv Bull 63:117-125

Croxall JP, Everson I, Kooyman GL, Ricketts C, Davis RW (1985) Fur seal diving behavior in relation to vertical distribution of krill. J Anim Ecol 54:1-8

Culik BM, Wilson RP, Bannash R (1994) Underwater swimming at low energetic cost by pygoscelid penguins. J Exp Biol 197:65-78

Dasgupta N, Alldredge JR 2002. A single-step method for identifying individual resources. J Agric Biol Env Stat 7: 208-221

Davis RW, Williams TM, Kooyman GL 1985. Swimming metabolism of yearling and adult harbor seals Phoca vitulina. Physiol Zool 58:590-596

Davis RW, Croxall JP, O'Connell MJ (1989) The reproductive energetics of gentoo (Pygoscelis papua) and macaroni (Eudyptes chrysolophus) penguin chicks. J Comp Physiol B 160:61-70

Demer DA, Hewitt RP (1995) Bias in acoustic biomass estimates of Euphausia superba due to diel vertical migration. Deep-Sea Res I 42:455-475

Frost BW, Bollens SM (1992) Variability of diel vertical migration in the marine planktonic copepod Pseudocalanus 
newmani in relation to its predators. Can J Fish Aquat Sci 49:1137-1141

Gliwicz MZ (1986) Predation and the evolution of vertical migration in zooplankton. Nature 320:746-748

Hecht T (1987) A guide to the otoliths of Southern Ocean fishes. S Afr J Antarct Res 17:1-87

Hewitt RP, Demer DA (1993) Dispersion and abundance of Antarctic krill in the vicinity of Elephant Island in the 1992 austral summer. Mar Ecol Prog Ser 99:29-39

Hill HJ (1990) A new method for the measurement of Antarctic krill Euphausia superba Dana from predator food samples. Polar Biol 10:317-320

Hooker SK, Boyd IL, Jessopp M, Cox O, Blackwell J, Boveng PL, Bengtson JL (2002) Monitoring the prey-field of marine predators: combining digital imaging with datalogging tags. Mar Mam Sci 18:680-697

Hunt GL, Harrison NM, Cooney T (1990) Foraging of least auklets: the influence of hydrographic structure and prey abundance. Stud Avian Biol 14:7-22

Jansen JK (1996) Ecological constraints on chinstrap penguin (Pygoscelis antarctica) foraging behavior: the role of diel and seasonal light changes. MS dissertation, University of Oregon, Eugene, OR

Jansen JK, Boveng PL, Bengtson JL (1998) Foraging modes of chinstrap penguins: contrasts between day and night. Mar Ecol Prog Ser 165:161-172

Jansen JK, Russell RW, Meyer WR (2002) Seasonal shifts in the provisioning behavior of chinstrap penguins, Pygoscelis antarctia. Oecologia 131:306-318

Johnson JB, Omland KS (2004). Model selection in ecology and evolution. Trends Ecol Evol 19:101-108

Kozlov AN, Shust KV, Zemsky AV (1990) Seasonal and interannual variability in the distribution of Electrona carlsbergi in the southern polar front area (the area to the north of Sough Georgia is used as an example). In: Selected Scientific Papers, 1990 (SC-CAMLR-SSR/7). CCAMLR, Hobart, p 337-367

Kim S, Siegel V, Hewitt R, Naganobu M, Demer DA, Ichii T, Kang S, Kawaguchi S and 7 others (1998) Temporal changes in marine environments in the Antarctic Peninsula area during the 1994/95 austral summer. Mem Natl Inst Polar Res (Jpn) Spec Issue 52:186-208

Makarov RP, Denys CJ (1981) Stages of sexual maturity of Euphausia superba Dana. Biomass Handbook no. 11. SCAR, Cambridge, p 1-13

Manly BFG, McDonald LL, Thomas DL, McDonald TL, Erickson WP (2002) Resource selection by animals: statistical design and analysis for field studies, 2nd edn. Kluwer Academic Publishers, Dordrecht

Miller LK (1978) Energetics of the northern fur seal in relation to climate and food resources of the Bering Sea. MMC75/08. US Marine Mammal Commission, Washington, DC

Orians GH, Pearson NE (1979) On the theory of central place foraging. In: Horn DJ, Mitchell RD, Stairs GR (eds) Analysis of ecological systems. Ohio State University Press, Columbus, OH, p 154-177

Osman LP, Hucke-Gaete R, Moreno CA, Torres D (2004) Feeding ecology of Antarctic fur seals at Cape Shirreff,
South Shetlands, Antarctica. Polar Biol 27:92-98

Pawitan Y (2001) In all likelihood: statistical modelling and inference using likelihood. Oxford University Press, New York

Pyke GH, Pulliam HR, Charnov EL (1977) Optimal foraging: a selective review of theory and tests. Q Rev Biol 52: $137-154$

R Development Core Team (2005) R: A language and environment for statistical computing. R Foundation for Statistical Computing, Vienna, available at: www.Rproject.org

SC-CAMLR (Scientific Committee for the Conservation of Antarctic Marine Living Resources) (1991) Report of the working group on krill. In: Report of the Tenth Meeting of the CCAMLR, Hobart, p109-204

Sabourenkov EN (1990) Mesopelagic fish of the Southern Ocean-summary results of recent Soviet studies. In: Selected Scientific Papers, 1990 (SC-CAMLR-SSP/7), CCAMLR, Hobart, p 433-457

Siegel V (1986) Untersuchungen zur Biologie des antarktischen Krill, Euphausia superba, im Bereich der Bransfield Strasse und angrenzender Gebiete. Mitt Inst Seefischerei Hamburg 38:1-244

Shaffer SA, Costa DP, Weimerskirch H (2003) Foraging effort in relation to the constraints of reproduction in free-ranging albatrosses. Funct Ecol 17:66-74

Sokal RP, Rohlf FJ (1997) Biometry: the principles and practices of statistics in biological research, 3rd edn. Freeman, San Francisco, CA

Stephens DW, Krebs JR (1986) Foraging theory. Princeton University Press, Princeton, NJ

Walker BW, Boveng PL (1995) Effects of time-depth recorders on maternal foraging and attendance behavior of Antarctic fur seals (Arctocephalus gazella). Can J Zool 73: 1538-1544.

Waugh SM, Weimerskirch H, Cherel Y, Prince PA (2000) Contrasting strategies of provisioning and chick growth in two sympatrically breeding albatrosses at Campbell Island, New Zealand. Condor 102:804-813

Weimerskirch H (1998) How can a pelagic seabird provision its chick when relying on a distant food resource? Cyclic attendance at the colony, foraging decision and body condition in sooty shearwaters. J Anim Ecol 57: 99-109

Weimerskirch H, Cherel Y (1998) Feeding ecology of shorttailed shearwaters: breeding in Tasmania and foraging in the Antarctic? Mar Ecol Prog Ser 167:261-274

Weimerskirch H, Guionnet T, Martin J, Shaffer SA, Costa DP (2000) Fast and fuel efficient? Optimal use of wind by flying albatrosses. Proc R Soc Lond B 267:1869-1874

Williams R, McEldowney A (1990) A guide to the fish otoliths from waters off the Australian Antarctic Territory, Heard and Macquarie Islands. ANARE Res Notes $75: 1-173$

Williams TD (1995) The penguins. Oxford University Press, Oxford

Wilson RP (1984) An improved stomach pump for penguins and other seabirds. J Field Ornithol 55:109-112 
Appendix 1. Likelihood function for estimation of habitat selection indices

From Eq. (3), for instance, the log-likelihood component for the $k$ th individual of species $i$ with $j$ habitats $\left(L L_{i j k}\right)$ is then given by

$$
\begin{aligned}
L L_{i j k} & =-\frac{\left(m_{i k}-1\right)}{2} \log \sigma_{i}^{2}-\frac{1}{2} \log \left(m_{i k} \alpha_{i}^{2} \sigma_{b}^{2}+\sigma_{i}^{2}\right) \\
& -\frac{1}{2 \sigma_{i}^{2}}\left\{-\frac{\alpha_{i}^{2} \sigma_{b}^{2}}{m_{i k} \alpha_{i}^{2} \sigma_{b}^{2}+\sigma_{i}^{2}}\left\{\sum_{l=1}^{m_{i k}} t_{i j k l}-m_{i k}\left(\alpha_{i}+\alpha_{i} \beta_{i j}\right)\right\}^{2}+\frac{1}{2 \sigma_{i}^{2}} \sum_{l=1}^{m_{i k}}\left(t_{i j k l}-\alpha_{i}-\alpha_{i} \beta_{i j}\right)^{2}\right\}
\end{aligned}
$$

by integrating out the random effects by an individual. The parameters are estimated by maximizing the total log-likelihood summed over all individuals

Appendix 2. Construction of confidence intervals for the standardized habitat selection index

The confidence intervals for the standardized habitat selection indices with significance level were obtained using the logit-based interval of Burnham \& Anderson (1998),

$$
\left[w_{i j}^{L}, w_{i j}^{U}\right]
$$

where

$$
\begin{gathered}
W_{i j}^{L}=\frac{\hat{W}_{i j}}{\hat{W}_{i j}+\left(1-\hat{W}_{i j}\right) C} \\
w_{i j}^{U}=\frac{\hat{W}_{i j}}{\hat{W}_{i j}+\left(1-\hat{W}_{i j}\right) / C} \\
C=\exp \left[\frac{z_{1-\alpha / 2} \hat{S e}\left(\hat{W}_{i j}\right)}{\hat{W}_{i j}\left(1-\hat{W}_{i j}\right)}\right]
\end{gathered}
$$

Editorial responsibility: Otto Kinne (Editor-in-Chief), Oldendorf/Luhe, Germany
Submitted: July 19, 2004; Accepted: January 2, 2007 Proofs received from author(s): August 1, 2007 